Article

\title{
First-Principles Calculations of the Electronic Structure and Optical Properties of Yttrium-Doped ZnO Monolayer with Vacancy
}

\author{
Qian Wu ${ }^{1}$, Ping Wang ${ }^{1, *(\mathbb{D}}$, Yan Liu ${ }^{1}$, Han Yang ${ }^{1}$, Jingsi Cheng ${ }^{1}$, Lixin Guo ${ }^{1,2}$, Yintang Yang ${ }^{3}$ \\ and Zhiyong Zhang ${ }^{4}$ \\ 1 State Key Laboratory of Integrated Services Networks, School of Telecommunications Engineering, \\ Xidian University, Xi'an 710071, China; qianwu0527@163.com (Q.W.); yanliu@stu.xidian.edu.cn (Y.L.); \\ 18829029375@163.com (H.Y.); jingsicheng@stu.xidian.edu.cn (J.C.); lxguo@xidian.edu.cn (L.G.) \\ 2 School of Physics and Optoelectronic Engineering, Xidian University, Xi'an 710071, China \\ 3 School of Microelectronics, Xidian University, Xi'an 710071, China; ytyang@xidian.edu.cn \\ 4 School of Information Science \& Technology, Northwest University, Xi'an 710127, China; \\ zhangzy@nwu.edu.cn \\ * Correspondence: pingwang@xidian.edu.cn; Tel.: +86-1365-923-8942
}

Received: 20 November 2019; Accepted: 2 February 2020; Published: 5 February 2020

\begin{abstract}
The electronic structures and optical characteristics of yttrium (Y)-doped ZnO monolayers (MLs) with vacancy (zinc vacancy, oxygen vacancy) were investigated by the first-principles density functional theory. Calculations were performed with the GGA+U (generalized gradient approximation plus $U$ ) approach, which can accurately estimate the energy of strong correlation semiconductors. The results show that the formation energy values of Y-doped ZnO MLs with zinc or oxygen vacancy $\left(\mathrm{V}_{\mathrm{Zn}}, \mathrm{V}_{\mathrm{O}}\right)$ are positive, implying that the systems are unstable. The bandgap of $\mathrm{Y}-\mathrm{V}_{\mathrm{Zn}}-\mathrm{ZnO}$ was $3.23 \mathrm{eV}$, whereas that of $\mathrm{Y}-\mathrm{V}_{\mathrm{O}}-\mathrm{ZnO}$ was $2.24 \mathrm{eV}$, which are smaller than the bandgaps of pure $\mathrm{ZnO} \mathrm{ML}$ and $\mathrm{Y}$-doped $\mathrm{ZnO}$ MLs with or without $\mathrm{V}_{\mathrm{O}}$. Impurity levels appeared in the forbidden band of $\mathrm{ZnO}$ MLs with $\mathrm{Y}$ and vacancy. Furthermore, $\mathrm{Y}-\mathrm{V}_{\mathrm{Zn}}-\mathrm{ZnO}$ will result in a red-shift of the absorption edge. Compared with the pure $\mathrm{ZnO} M L, \mathrm{ZnO}$ MLs with one defect $\left(\mathrm{Y}, \mathrm{V}_{\mathrm{Zn}}\right.$ or $\left.\mathrm{V}_{\mathrm{O}}\right)$, and $\mathrm{Y}-\mathrm{V}_{\mathrm{Zn}}-\mathrm{ZnO}$, the absorption coefficient of $\mathrm{Y}-\mathrm{V}_{\mathrm{O}}-\mathrm{ZnO}$ was significantly enhanced in the visible light region. These findings demonstrate that $\mathrm{Y}-\mathrm{V}_{\mathrm{O}}-\mathrm{ZnO}$ would have great application potential in photocatalysis.
\end{abstract}

Keywords: $\mathrm{ZnO}$ monolayer; yttrium; vacancy; electronic structure; optical properties; first-principles calculations

\section{Introduction}

Since the third scientific and technological revolution, energy has become essential for economic development. At present, fossil energy, such as oil, natural gas, and coal, is the most consumed energy in the world. However, the energy resources on earth are limited, and these fossil fuels will rapidly run out in the first half of the 21st century. Therefore, the vigorous development of renewable energy is not only conducive for sustainable economic development but also for alleviating the increasingly serious energy and environmental problems. As a potential renewable energy source, solar energy, especially visible light (which accounts for most of the solar energy), is believed to contribute to mitigating these problems through photocatalytic technology (also known as semiconductor-based photocatalytic technology) [1]. Semiconductor-based photocatalysis has attracted considerable attention due to its direct conversion of solar energy to easily stored hydrogen, as well as free secondary pollution [2,3]. The basic principle of semiconductor-based photocatalytic technology is the energy band theory of solids. Under visible light 
irradiation, the photons can be adsorbed to generate electrons $\left(\mathrm{e}^{-}\right)$in the conduction band (CB) and holes $\left(h^{+}\right)$in the valence band $(\mathrm{VB})$ once their energy is greater than the bandgap energy $\left(\mathrm{E}_{\mathrm{g}}\right)$ of the semiconductor photocatalyst. These photo-generated charge carriers will react with surface molecules (such as $\mathrm{H}_{2} \mathrm{O}$, adsorbed $\mathrm{O}_{2}$ ) to undergo secondary reactions to produce radical species $\left(\mathrm{OH}, \mathrm{O}_{2}^{-}\right)$, which further react with the organic compounds and reduce them to harmless products [4,5]. Since the water splitting phenomenon with titanium dioxide $\left(\mathrm{TiO}_{2}\right)$ and platinum as electrodes was discovered in 1972, semiconductor photocatalysts, such as $\mathrm{TiO}_{2}, \mathrm{CdO}$, and $\mathrm{ZnO}$, have been widely investigated due to their excellent electronic and optical properties, non-toxicity, and low cost [6-8]. As a kind of II-VI compound semiconductor, $\mathrm{ZnO}$ can also serve as a high-activity semiconductor photocatalyst because it has high chemical stability, high carrier mobility, large exciton binding energy $(60 \mathrm{meV})$, mature synthesis technology, and tunable properties [9-11]. However, the wide bandgap (3.37 eV) of $\mathrm{ZnO}$ will result in low absorbability (4\%) under sunlight irradiation [12], which is not conducive to the photocatalytic utilization of $\mathrm{ZnO}$ in the visible light region. To enhance the photocatalytic efficiency, various synthesis methods and surface modifications (doping, composite, and deposition) have been adopted to change the crystal structure, size, morphology, and bandgap [13]. Metal doping can effectively promote the visible light harvesting ability of catalysts [14-20]. Yttrium (Y) is an environmentally-friendly and abundant rare earth (RE) element [21]. The radius of yttrium is close to the atomic radius of zinc $(\mathrm{Zn})$, which facilitates the insertion of $\mathrm{Y}$ ions into the $\mathrm{ZnO}$ lattice [22]. So far, some studies on $\mathrm{Y}$-doped $\mathrm{ZnO}$ have shown that impurity levels could be introduced in the forbidden band by $\mathrm{Y}$ doping, and the valence electron transition with low-energy excitation could improve the utilization of visible light [23-26]. The authors in [21,27] observed that the optical transmittance of Y-doped $\mathrm{ZnO}$ films in the visible spectral range diminishes with yttrium doping, suggesting that the absorption coefficient increases in the visible light region.

During preparation, $\mathrm{ZnO}$ will exhibit intrinsic defects, such as zinc vacancy $\left(\mathrm{V}_{\mathrm{Zn}}\right)$ and oxygen vacancy $\left(\mathrm{V}_{\mathrm{O}}\right)$, and the role of these vacancy defects in the optical properties of $\mathrm{ZnO}$ has been explored experimentally and theoretically [28-30]. Tang et al. [28] found that $\mathrm{V}_{\mathrm{O}}$ narrowed the bandgap of $\mathrm{ZnO}$, and the results of photocatalytic experiments reflected that $\mathrm{V}_{O}$ can not only act as impurity levels in the band structure of $\mathrm{ZnO}$ but also function as electron traps to accept the photo-generated electrons. Wang et al. [29] prepared pristine $\mathrm{ZnO}$ films, and found that the introduction of the green luminescence is correlated with the formation of the $\mathrm{Zn}$ vacancy-related defect $\left(\mathrm{V}_{\mathrm{Zn}}\right)$. Theoretical studies of the effect of vacancy defects in metal element-doped $\mathrm{ZnO}$ were performed in [31-36]. Bai et al. [31] studied the electronic and optical properties of $2 \mathrm{D} \mathrm{ZnO}: \mathrm{Mg} / \mathrm{Be}$ with $\mathrm{V}_{\mathrm{O}}$ or $\mathrm{V}_{\mathrm{Zn}}$. The results indicated that $V_{O}$ will cause a blue-shift, whereas $V_{Z n}$ will cause a red-shift in the optical absorption spectra. Alessandra et al. [32] presented a first-principles study on the effect of native point defects in $\mathrm{Al}: \mathrm{ZnO}$ transparent conductive oxide. They found that $\mathrm{V}_{\mathrm{O}}$ defects maintain the electrical properties but worsen the transparency of native $\mathrm{Al}: \mathrm{ZnO}$, whereas $\mathrm{V}_{\mathrm{Zn}}$ defects are strong electron acceptors that can destroy the metal-like conductivity of the system. Meng et al. [33] studied the formation energies, electronic, and optical properties of pure $\mathrm{ZnO}$ and Er-doped $\mathrm{ZnO}$ with and without incorporating the intrinsic point defects (IPDs). The strong interactions between the Er dopant and acceptor-type IPDs in ZnO were perceived as one of the important reasons for the strong light absorption in the visible and infrared regions. For the yttrium element, Li et al. [36] calculated the electronic and ferromagnetic properties of a Y-doped $\mathrm{ZnO}$ (0001)-Zn polar surface with and without point defects. The calculated results showed that $V_{Z n}$ is an acceptor that can trap electrons to balance the electrovalence, and $V_{O}$ can introduce an impurity level in the bandgap near the Fermi level.

Until now, most studies on yttrium element-doped $\mathrm{ZnO}$ have focused on bulk, surface, and thin film forms $[21,23,36]$. Compared with these forms, ZnO ML of two-dimensional (2D) material has unique properties, such as larger surface areas, furnishing photocatalytic reaction sites, and a shorter transportation path for the photo-induced carriers, which are beneficial to promote photocatalytic performance $[37,38]$. Freeman et al. [39,40] firstly predicted the two-dimensional layered phase of $\mathrm{ZnO}$, and they found that the $2 \mathrm{D}$ structure of $\mathrm{ZnO}$ prefers a graphitic-like structure when the number 
of $\mathrm{ZnO}$ (0001) layers is reduced, due to the depolarization of the surface. Experimentally, Deng et al. [41] synthesized a $\mathrm{ZnO}$ ML by reactive deposition of $\mathrm{Zn}$ on $\mathrm{Au}$ (111), which confirmed the existence of a ZnO ML graphite-like structure. Tan et al. [42] investigated the structural, electronic, and magnetic properties of RE metals ( $\mathrm{RE}=\mathrm{Y}, \mathrm{Ce}, \mathrm{Eu}, \mathrm{Gd}$, and Dy) doped $\mathrm{ZnO} \mathrm{ML}$ using the $\mathrm{DMol}^{3}$ package. The ZnO ML with Ce, Eu, Gd, or Dy was magnetic, but Y-doped ZnO ML was a nonmagnetic semiconductor. ZnO ML undergoes a transition from semiconductor to metal with the presence of $Y$ doping. Although the electronic and optical properties of $\mathrm{ZnO} M L$ with yttrium $(\mathrm{Y})$ or vacancies have been described, the structural and optical properties of yttrium-doped ZnO ML with vacancy defect $\left(\mathrm{V}_{\mathrm{Zn}}\right.$ or $\left.\mathrm{V}_{\mathrm{O}}\right)$ have not been investigated yet.

In this work, the first-principles calculations of yttrium (Y)-doped $\mathrm{ZnO} M L$ with zinc vacancy $\left(\mathrm{V}_{\mathrm{Zn}}\right)$ or oxygen vacancy $\left(\mathrm{V}_{\mathrm{O}}\right)$ are performed. For comparison, pristine $\mathrm{ZnO} \mathrm{ML}$ and $\mathrm{ZnO}$ MLs with $\mathrm{Y}$ or vacancy are also calculated. The crystal structures and formation energies of pure $\mathrm{ZnO} M L$ and $\mathrm{ZnO}$ ML with $Y$ or vacancy are studied to ensure the rationality of the models. The electronic structures and optical properties of the $\mathrm{ZnO}$ ML doping systems are obtained, analyzed, and compared. This work also analyzes the possible photocatalytic reaction mechanism to further understand the photocatalytic principle of $\mathrm{Y}$ doping with vacancy on ZnO MLs.

\section{Calculation Method}

First-principles calculations were performed on the basis of the density functional theory (DFT) [43]. Compared with LDA (local density approximation) functionals, GGA (generalized gradient approximation) functionals (including PW91 [Perdew-Wang 91], PBE [Perdew-Burke-Ernzerhof] and RPBE [Revised-Perdew-Burke-Ernzerhof]) have more precise energy and structure and are more suitable for open systems. PW91 was first proposed by Perdew et al. in 1991 [44]. PBE was first proposed by Perdew and Burke in 1996. Improvements over PW91 include an accurate description of the linear response of the uniform electron gas, correct behavior under uniform scaling, and a smoother potential [45]. RPBE was first proposed in 1998 with improvements in the chemisorption energy of atoms and molecules [46]. Therefore, we adopted the GGA with PBE function as the correlation function [47], and the exchange-correlation interaction between ions and electrons was described by ultrasoft pseudopotentials [48]. The valence electron orbitals for $\mathrm{Zn}, \mathrm{O}$, and $\mathrm{Y}$ were chosen as $\mathrm{Zn}$ $3 \mathrm{~d}^{10} 4 \mathrm{~s}^{2}, \mathrm{O} 2 \mathrm{~s}^{2} 2 \mathrm{p}^{4}$, and $\mathrm{Y} 4 \mathrm{~d}^{1} 5 \mathrm{~s}^{2}$, respectively. In this work, all the calculations of structural stability, electronic, and optical properties of $\mathrm{ZnO} \mathrm{ML}$ with and without $\mathrm{Y}$ or vacancy were performed by CASTEP (Cambridge Sequential Total Energy Package). Geometry optimization was performed with all atoms moving freely and cells optimized fully. In order to investigate the impact of $Y$ and vacancy doping concentration on the stability of $\mathrm{ZnO} M L$, models of $2 \times 2 \times 1,3 \times 3 \times 1$, and $4 \times 4$ $\times 1$ supercells were considered. The co-existence of $Y$ and vacancy in $\mathrm{ZnO}$ ML was investigated in the most stable doping models. The plane-wave cutoff energy was $400 \mathrm{eV}$, the Monkhorst-Pack grid of k-point sampling was set to $4 \times 4 \times 2$ in the Brillouin zone (BZ) [49]. In the self-consistent field calculation, the convergence precision of the energy charge was $1.0 \times 10^{-5} \mathrm{eV} / \mathrm{atom}$, the maximum displacement convergence criterion was $1.0 \times 10^{-3} \AA$, the maximum force acting on each atom was $0.03 \mathrm{eV} / \AA$, and the maximum stress was $0.05 \mathrm{GPa}$. A vacuum region of $15 \AA$ was applied along the $\mathrm{z}$-direction above the $\mathrm{ZnO} \mathrm{ML}$ to avoid the interactions caused by periodic boundary conditions. The intrinsic coordinates and crystal parameters were completely relaxed in the geometric optimization. The GGA+U method was adopted to optimize the energy of systems and correct the bandgap value of $\mathrm{ZnO} M L$ [50]. The Hubbard parameters $\mathrm{U}_{\mathrm{d}, \mathrm{Zn}}$ of $10 \mathrm{eV}$ [51], $\mathrm{U}_{\mathrm{p}, \mathrm{O}}$ of $7 \mathrm{eV}$ [51], and $\mathrm{U}_{\mathrm{d}, \mathrm{Y}}$ of $2 \mathrm{eV}$ [23] were employed. Besides this, all the calculations were performed under spin polarization and the same U parameters. 


\section{Results and Discussion}

\subsection{Crystal Structure and Structural Stability}

To better study the properties of the ZnO ML with Y or vacancy, the crystal structure and stability of the $\mathrm{ZnO} \mathrm{ML}$ should be investigated first. ZnO ML was acquired by cutting the bulk wurtzite $\mathrm{ZnO}$ with (0001) polar surface. The top view of the optimized ZnO ML is shown in Figure 1a, which illustrates a graphene-like structure. Each atom in the ZnO ML was three-fold coordinated, which is different from the four-fold coordinate $\mathrm{Zn}$ and $\mathrm{O}$ atoms in the bulk wurtzite structure [52]. Figure 1b shows the side view of the original and optimized $\mathrm{ZnO}$ MLs. The side view of the original $\mathrm{ZnO} \mathrm{ML}$ was a ripple surface [53] because it retained the wurtzite structure of bulk $\mathrm{ZnO}\left(\alpha=90^{\circ}, \beta=90^{\circ}\right.$, $\gamma=120^{\circ}$ ). However, the side view of the optimized $\mathrm{ZnO}$ ML became flat, the $\mathrm{O}-\mathrm{Zn}-\mathrm{O}$ bond angle was $120^{\circ}$, and the bond length between $\mathrm{Zn}$ and $\mathrm{O}$ atoms was $1.895 \AA$, which agrees well with the previous theoretical values [54,55]. The $\mathrm{Zn}-\mathrm{O}$ bond length in the $\mathrm{ZnO} \mathrm{ML}$ was smaller than the corresponding bond length in bulk $\mathrm{ZnO}(2.01 \AA)$. This discrepancy is due to the stronger $\mathrm{sp}^{2}$ orbital hybridization of $\mathrm{ZnO}$ in the $2 \mathrm{D}$ structure than the $\mathrm{sp}^{3}$ orbital hybridization in bulk $\mathrm{ZnO}$ [43].

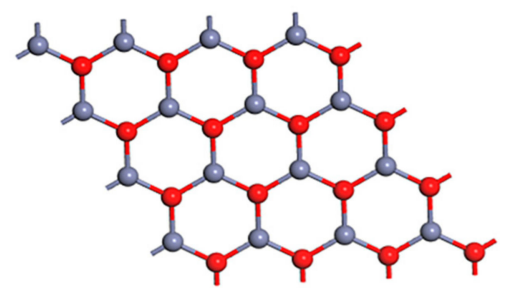

(a)

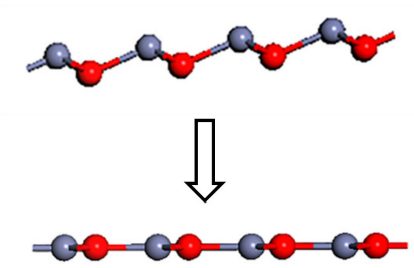

(b)

Figure 1. Graphene-like ZnO ML with $4 \times 4 \times 1$ supercell. (a) The top view, (b) the side view of the original and the optimized structure.

To assess the stability of the $\mathrm{ZnO} \mathrm{ML}$ with and without $\mathrm{Y}$ or vacancy, the formation energies of the $\mathrm{ZnO}$ MLs were calculated. The formation energy $\left(E_{f}\right)$ can be calculated by the following [56]:

$$
E_{f}=E_{\text {defect }}-E_{\text {perfect }}-\sum_{i} n_{i} \mu_{i}
$$

Here, $E_{\text {defect }}$ is the total energy of $\mathrm{ZnO} M L$ with defect $\left(\mathrm{Y}, \mathrm{V}_{\mathrm{Zn}}, \mathrm{V}_{\mathrm{O}}\right), E_{\text {perfect }}$ is the total energy of the pristine ZnO ML without any impurity or vacancy, $n_{i}$ is the number of atoms of type $i$ added to $\left(n_{i}>0\right)$ or removed from $\left(n_{i}<0\right)$ the initial system, and $\mu_{i}$ is the chemical potential of an atom of type $i$ [15]. The $\mu_{i}$ is the chemical potential obtained from the energy of one zinc or yttrium atom in a large 2D supercell (i.e., $\mu_{Y}=-188.521 \mathrm{eV}, \mu_{\mathrm{Zn}}=-1708.148 \mathrm{eV}, \mu_{\mathrm{O}}=-429.571 \mathrm{eV}$ ).

Figure 2 shows the formation energies of ZnO MLs with and without $Y$ or vacancy. As shown in the figure, all formation energy values of Y single-doped ZnO ML were negative, indicating that Y-doped $\mathrm{ZnO}$ ML can spontaneously form in the experiment. The formation energy value of $\mathrm{Y}$ single-doped $\mathrm{ZnO} \mathrm{ML}$ changed from $-1.428 \mathrm{eV}$ to $-0.188 \mathrm{eV}$ with increasing $\mathrm{Y}$ concentration. Hence, $\mathrm{ZnO} \mathrm{ML}$ can be inferred to be the most stable system when the doping concentration of $Y$ is 6.25 at.\%. Besides this, the formation energy of $\mathrm{V}_{\mathrm{Zn}}-\mathrm{ZnO}$ was close to that of $\mathrm{V}_{\mathrm{O}}-\mathrm{ZnO}$, which were both positive. This finding indicates that the systems are unstable, and $\mathrm{V}_{\mathrm{O}}-\mathrm{ZnO}$ seems less unstable than $\mathrm{V}_{\mathrm{Zn}}-\mathrm{ZnO}$. Hussain et al. [57] reached a similar conclusion by studying $\mathrm{ZnO}$ nano sheets. Therefore, the $4 \times 4 \times 1$ supercell model was chosen for $\mathrm{ZnO} \mathrm{ML}$ with $\mathrm{Y}$ and vacancy. The formation energy values of $\mathrm{Y}$-doped $\mathrm{ZnO}$ $\mathrm{ML}$ with $\mathrm{V}_{\mathrm{Zn}}$ or $\mathrm{V}_{\mathrm{O}}$ were positive, indicating the instability of the systems. Figure 3a-d show the optimized structures of $\mathrm{ZnO} M L$ with $\mathrm{V}_{\mathrm{Zn}}, \mathrm{ZnO} \mathrm{ML}$ with $\mathrm{V}_{\mathrm{O}}, \mathrm{ZnO} \mathrm{ML}$ with $\mathrm{Y}$ and $\mathrm{V}_{\mathrm{Zn}}$, and $\mathrm{ZnO} \mathrm{ML}$ with $\mathrm{Y}$ and $\mathrm{V}_{\mathrm{O}}$, called $\mathrm{V}_{\mathrm{Zn}}-\mathrm{ZnO}, \mathrm{V}_{\mathrm{O}}-\mathrm{ZnO}, \mathrm{Y}-\mathrm{V}_{\mathrm{Zn}}-\mathrm{ZnO}$, and $\mathrm{Y}-\mathrm{V}_{\mathrm{O}}-\mathrm{ZnO}$, respectively. 


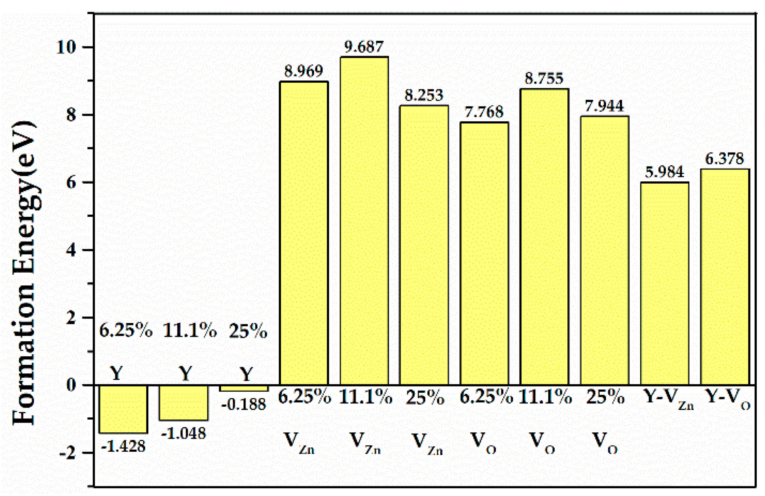

Figure 2. The formation energies of $\mathrm{ZnO}$ MLs with $\mathrm{Y}, \mathrm{V}_{\mathrm{Zn}}, \mathrm{V}_{\mathrm{O}}$, and $\mathrm{ZnO}$ MLs with $\mathrm{Y}$ and vacancy.

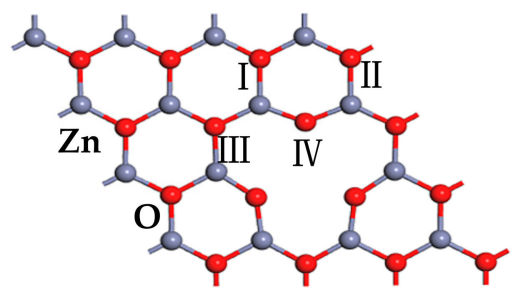

(a)

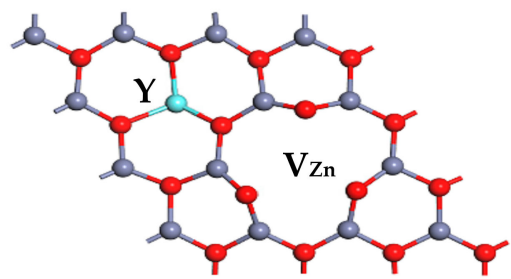

(c)

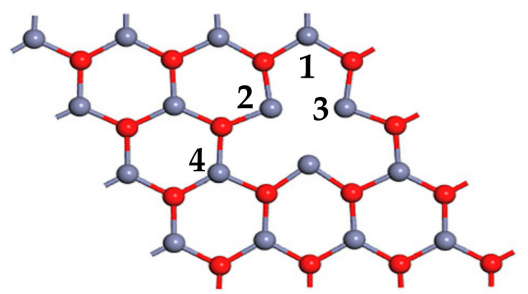

(b)

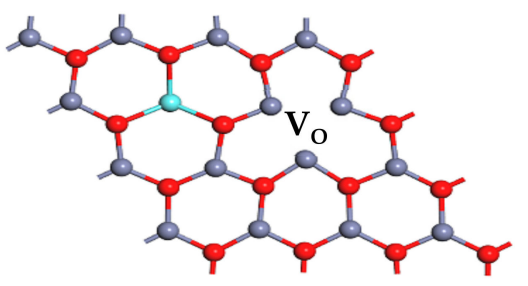

(d)

Figure 3. The optimized ZnO MLs with (a) $V_{Z n}$, (b) $V_{O}$, (c) $Y$ and $V_{Z n}$, (d) $Y$ and $V_{O}$.

Figure $3 \mathrm{a}, \mathrm{b}$ and Table 1 clearly show that the $\mathrm{ZnO} \mathrm{ML}$ exhibited a distortion because of the vacancy. Compared with the $\mathrm{Zn}-\mathrm{O}$ bond in $\mathrm{ZnO} \mathrm{ML}$, the $\mathrm{Zn}-\mathrm{O}$ bond lengths adjacent to $\mathrm{V}_{\mathrm{Zn}}$ in Figure 3 a decreased to different degrees (as shown in Table 1), whereas the Zn-O bond lengths closest to $V_{O}$ in Figure $3 b$ increased slightly. The charge effect can be used to explain the changes in bond lengths and bond angles associated with the vacancies. A zinc atom is removed from the monolayer to form $\mathrm{V}_{\mathrm{Zn}}$, and two negative charges are left in the monolayer. Therefore, other positively-charged zinc atoms would move toward $\mathrm{V}_{\mathrm{Zn}}$. By contrast, the neighbouring oxygen atoms with negative charges would not be attracted by static electricity and would move further away. Therefore, the $\mathrm{Zn}-\mathrm{O}$ bond lengths near the $V_{Z n}$ would be shortened, explaining the changes in the bond angle. For $V_{Z n}$, both zinc and oxygen moved closer to an oxygen site when the oxygen was removed [58]. In addition, the lattice parameters of $\mathrm{ZnO} \mathrm{ML}, \mathrm{Y}-\mathrm{ZnO}, \mathrm{V}_{\mathrm{Zn}}-\mathrm{ZnO}, \mathrm{V}_{\mathrm{O}}-\mathrm{ZnO}, \mathrm{Y}-\mathrm{V}_{\mathrm{Zn}}-\mathrm{ZnO}$, and $\mathrm{Y}-\mathrm{V}_{\mathrm{O}}-\mathrm{ZnO}$ were 3.282, $3.329,3.281,3.282,3.282$, and $3.290 \AA$, respectively. The results indicate that the lattice constant of $\mathrm{ZnO}$ increased by $\mathrm{Y}$ doping, the lattice constant of $\mathrm{ZnO}$ decreased slightly by the presence of $\mathrm{V}_{\mathrm{Zn}}$, and $\mathrm{V}_{\mathrm{O}}$ had little effect on the lattice constant of $\mathrm{ZnO}$. The ionic radius of $\mathrm{Y}^{3+}(0.9 \AA)$ was larger than that of $\mathrm{Zn}^{2+}(0.74 \AA)$, which increased the lattice parameter a of $\mathrm{ZnO} \mathrm{ML}$. The removal of the zinc and oxygen atoms resulted in a small change in the lattice parameters of $\mathrm{ZnO} M L$. 
Table 1. Bond length $d$ and bond angle $\theta$ of $\mathrm{ZnO} \mathrm{ML}, \mathrm{V}_{\mathrm{Zn}}-\mathrm{ZnO}$, and $\mathrm{V}_{\mathrm{O}}-\mathrm{ZnO}$ (the atomic number is labeled in Figure 3).

\begin{tabular}{|c|c|c|c|c|}
\hline Doping System & Bond & $d(\AA)$ & $\Theta$ & Value $\left({ }^{\circ}\right)$ \\
\hline \multirow{2}{*}{$\mathrm{ZnO} \mathrm{ML}$} & $\mathrm{Zn}-\mathrm{O}$ & 1.895 & $\mathrm{Zn}-\mathrm{O}-\mathrm{Zn}$ & 120 \\
\hline & & & $\mathrm{O}-\mathrm{Zn}-\mathrm{O}$ & 120 \\
\hline \multirow{3}{*}{$\mathrm{V}_{\mathrm{Zn}}-\mathrm{ZnO}$} & $\mathrm{Zn}_{2}-\mathrm{O}_{\mathrm{IV}}$ & 1.884 & $\mathrm{O}_{\mathrm{IV}}-\mathrm{Zn}_{2}-\mathrm{O}_{\mathrm{III}}$ & 128.185 \\
\hline & $\mathrm{Zn}_{2}-\mathrm{O}_{\mathrm{III}}$ & 1.806 & $\mathrm{Zn}_{2}-\mathrm{O}_{\mathrm{III}}-\mathrm{Zn}_{4}$ & 116.496 \\
\hline & & & $\mathrm{Zn}_{2}-\mathrm{O}_{\mathrm{IV}}-\mathrm{Zn}_{3}$ & 132.858 \\
\hline \multirow{3}{*}{$\mathrm{V}_{\mathrm{O}}-\mathrm{ZnO}$} & $\mathrm{Zn}_{2}-\mathrm{O}_{\mathrm{I}}$ & 1.920 & $\mathrm{Zn}_{1}-\mathrm{O}_{\mathrm{I}}-\mathrm{Zn}_{2}$ & 115.810 \\
\hline & $\mathrm{Zn}_{1}-\mathrm{O}_{\mathrm{I}}$ & 1.891 & $\mathrm{O}_{\mathrm{I}}-\mathrm{Zn}_{1}-\mathrm{O}_{\mathrm{II}}$ & 113.397 \\
\hline & & & $\mathrm{O}_{\mathrm{I}}-\mathrm{Zn}_{2}-\mathrm{O}_{\mathrm{III}}$ & 115.772 \\
\hline
\end{tabular}

\subsection{Electronic Structure}

\subsubsection{The Pristine ZnO ML and ZnO MLs with Y or Vacancy}

The calculated band structures for pure $\mathrm{ZnO} \mathrm{ML}$ and $\mathrm{ZnO}$ MLs with yttrium or vacancy (Y-ZnO, $\mathrm{V}_{\mathrm{Zn}}-\mathrm{ZnO}, \mathrm{V}_{\mathrm{O}}-\mathrm{ZnO}$ ) are presented in Figure 4. From Figure $4 \mathrm{a}, \mathrm{b}$, both valence band maximum (VBM) and conduction band minimum (CBM) were situated at the $\mathrm{G}$ point, indicating a direct bandgap. In Figure $4 \mathrm{a}$, the bandgap of pure $\mathrm{ZnO} \mathrm{ML}(4.03 \mathrm{eV})$ is greater than bulk $\mathrm{ZnO}$ (3.37 eV) [12], which can be explained by the quantum confinement effects, and it was confirmed theoretically and experimentally [59]. In addition, the energy band structures of the spin-up and spin-down components were symmetrical, indicating that the pristine $\mathrm{ZnO} \mathrm{ML}$ is a non-magnetic semiconductor. From Figure $4 \mathrm{~b}, \mathrm{Y}-\mathrm{ZnO}$ is a direct bandgap semiconductor with a bandwidth of $4.56 \mathrm{eV}$, which is larger than that of ZnO ML. It was noted that the Fermi level of $\mathrm{Y}-\mathrm{ZnO}$ moved up and located approximately at the CBM, which produced a degenerate n-type semiconductor. This degenerate n-type semiconductor showed the Burstein-Moss effect [20]. A new impurity level appeared because of $Y$ doping, and this impurity was located near the Fermi level in the energy band structure of the spin-up channel. The impurity level can serve as an effective recombination center and increases the separation rate of $\mathrm{e}^{-}$and $\mathrm{h}^{+}$when $\mathrm{ZnO}$ is illuminated by a light source. In addition, the energy band structures of the spin-up and spin-down channels were asymmetrical, implying that Y-ZnO is a magnetic semiconductor. Figure $4 \mathrm{c}$ clearly shows that the Fermi level of $\mathrm{V}_{\mathrm{Zn}}-\mathrm{ZnO}$ moved slightly to the lower energy level, indicating that $\mathrm{V}_{\mathrm{Zn}}-\mathrm{ZnO}$ is a degenerate p-type semiconductor, and shallow acceptor states were created around the Fermi level in the VBM, increasing the carrier concentration. For $\mathrm{V}_{\mathrm{O}}-\mathrm{ZnO}$, the forbidden bandgap increased, and the Fermi level shifted towards the higher energy region compared with the intrinsic ZnO ML, as shown in Figure 4d. Thus, the VB may be inferred to be completely occupied by electrons. On the other hand, the spin-up and spin-down components of $\mathrm{V}_{\mathrm{Zn}}-\mathrm{ZnO}$ and $\mathrm{V}_{\mathrm{O}}-\mathrm{ZnO}$ were symmetrical, indicating the absence of magnetism for the $\mathrm{ZnO} M L$ with vacancy.

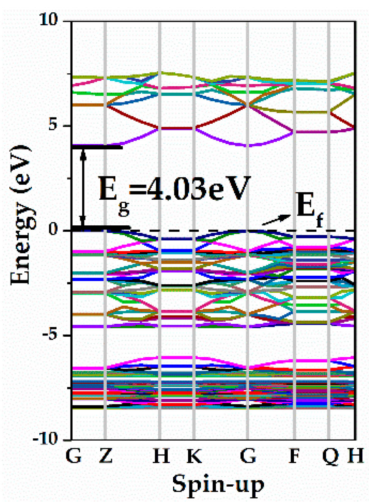

(a)

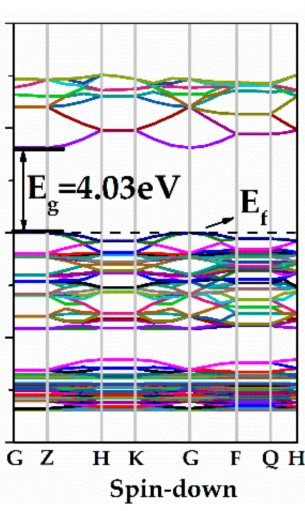

Spin-down

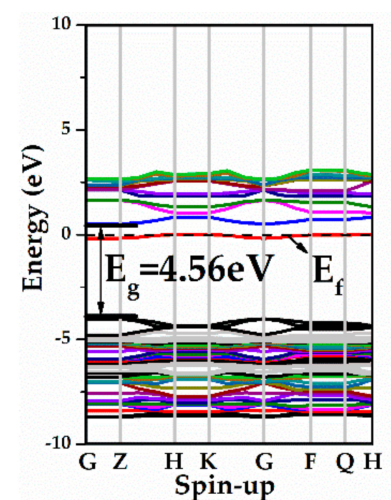

(b)

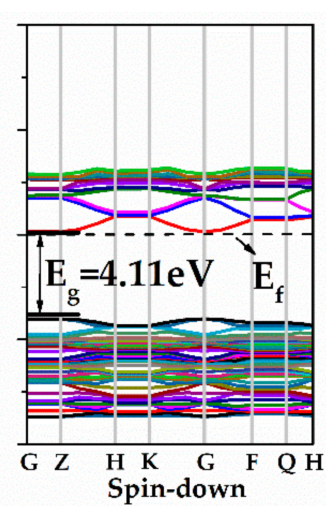

Spin-down

Figure 4. Cont. 


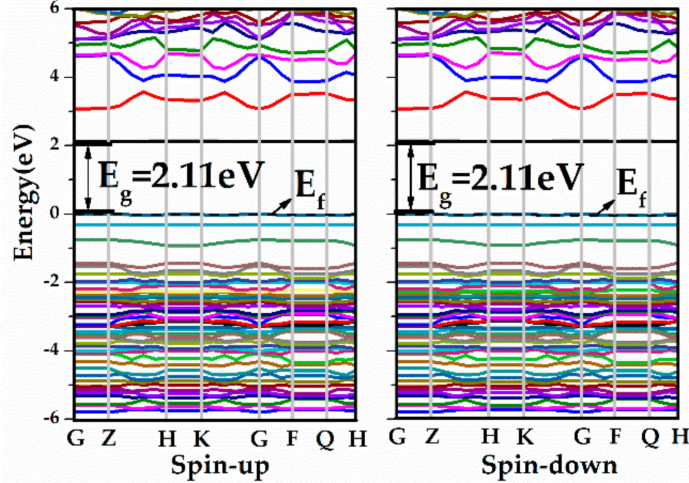

(c)
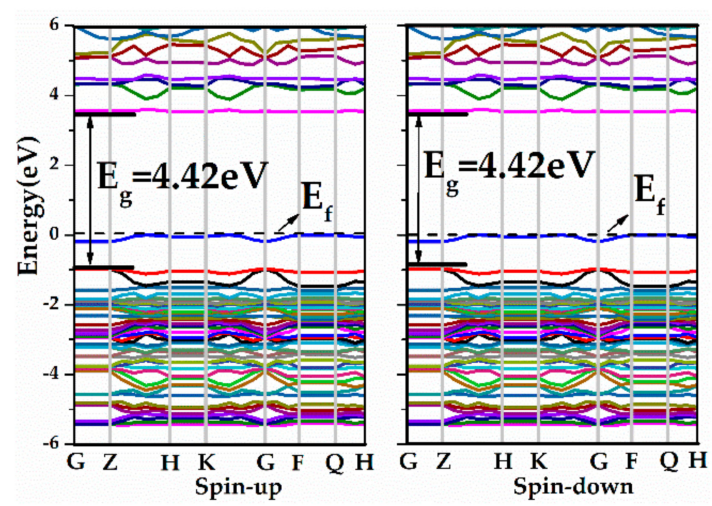

(d)

Figure 4. The band structures of (a) $\mathrm{ZnO} M L$, (b) $\mathrm{Y}-\mathrm{ZnO}$, (c) $\mathrm{V}_{\mathrm{Zn}}-\mathrm{ZnO}$, and (d) $\mathrm{V}_{\mathrm{O}}-\mathrm{ZnO}$.

Figure 5 plots the total and the partial density of states (TDOS, PDOS) of the pristine, Y single-doped $\mathrm{ZnO}$ MLs and ZnO MLs with vacancy, and these parameters were applied to analyze the distribution and occupancy of each related orbit of $\mathrm{Zn}, \mathrm{O}$, and $\mathrm{Y}$ elements. As shown in Figure 5a, the VB consisted of two parts: the lower part was composed of $\mathrm{Zn}-3 \mathrm{~d}$ and $\mathrm{O}-2 \mathrm{p}$ states, whilst the upper part was mainly dominated by O-2p states. The hybridization of the $\mathrm{Zn}-3 \mathrm{~d}$ and $\mathrm{O}-2 \mathrm{p}$ states occurred in the $\mathrm{VB}$, and the bonding states were formed in this energy region [18]. The CB was mainly ascribed to $\mathrm{Zn}-4 \mathrm{~s}$ and O-2p states. Therefore, the antibonding states in the CB of ZnO ML comprised Zn-4s and $\mathrm{O}-2 \mathrm{p}$ states [18]. From Figure 5b, the VB mainly consisted of O-2p and Zn-3d states, the VBM was determined by O-2p states, and the CB was mainly composed of Y-4d and Zn-4s states, with limited contribution from $\mathrm{O}-2 \mathrm{p}$ states. In addition, the chemical bonding of $\mathrm{Zn}, \mathrm{O}$, and $\mathrm{Y}$ atoms caused orbital hybridization between the $\mathrm{Y}$ atom and adjacent $\mathrm{Zn}$ and $\mathrm{O}$ atoms, and the electron density overlaps will increase with Y doping, which plays a crucial role in controlling the chemical properties of Y-ZnO. This process will also lead to the splitting of the donor energy level and expansion into an impurity band. Therefore, $\mathrm{Y}$ doping has a great impact on ZnO ML conductivity. In addition, the TDOS was asymmetrical, indicating that the spin-polarization mainly originated from the $4 \mathrm{~d}$ electrons of the $\mathrm{Y}$ atom. For $\mathrm{V}_{\mathrm{Zn}}-\mathrm{ZnO}$ and $\mathrm{V}_{\mathrm{O}}-\mathrm{ZnO}$, the bandgap of $\mathrm{ZnO}$ ML was mainly determined by $\mathrm{Zn}-4 \mathrm{~s}$ states in the CB and O-2p states in the VB. For oxygen vacancy, the VBM and CBM moved to a lower energy region, the presence of $\mathrm{V}_{\mathrm{O}}$ resulted in the splitting of the $\mathrm{VB}$ into two narrower bandgaps $(-2 \mathrm{eV}$ and $0 \mathrm{eV}$ ), as shown in Figure $5 \mathrm{~d}$. The upper energy level was located in the forbidden band, which is induced by oxygen vacancy [31]. The new energy level is beneficial to the transition of electrons under low-energy incident light. Moreover, vacancy could change the conductivity of ZnO ML by changing the carrier concentration near the Fermi level, which is similar to that of Y doping.

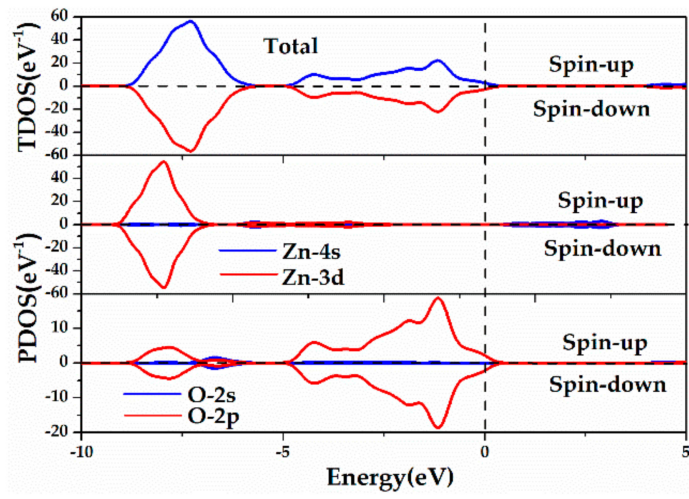

(a)

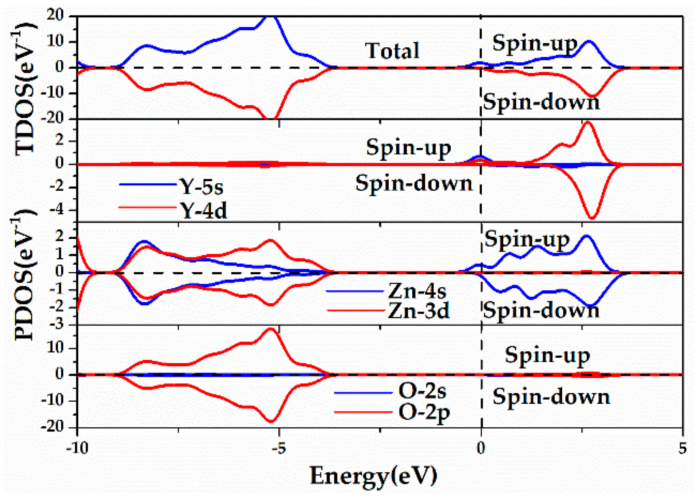

(b)

Figure 5. Cont. 


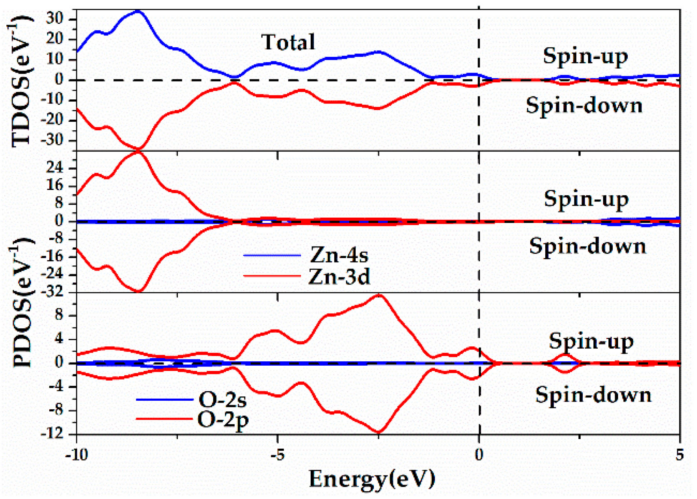

(c)

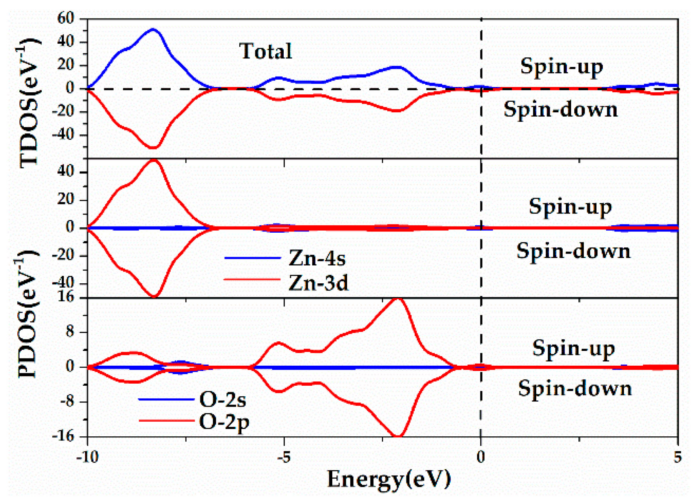

(d)

Figure 5. The calculated TDOS and PDOS (total and partial density of states) of (a) ZnO ML, (b) Y-ZnO, (c) $\mathrm{V}_{\mathrm{Zn}}-\mathrm{ZnO}$, and (d) $\mathrm{V}_{\mathrm{O}}-\mathrm{ZnO}$.

\subsubsection{Y-doped ZnO MLs with Vacancy}

The effects of $\mathrm{V}_{\mathrm{Zn}}$ and $\mathrm{V}_{\mathrm{O}}$ on the electronic structure of Y-doped $\mathrm{ZnO}$ ML were investigated. Figure 6 shows the energy band structures of $Z n O$ MLs with $Y$ and vacancy $\left(V_{Z n}\right.$ or $\left.V_{O}\right)$, which were calculated by the GGA+U method. From Figure $6 a$, the VBM and CBM of $Y-V_{Z n}-Z n O$ were located at the $G$ point, suggesting that $Y-\mathrm{V}_{\mathrm{Zn}}-\mathrm{ZnO}$ is a direct bandgap semiconductor. The bandgap of $\mathrm{Y}-\mathrm{V}_{\mathrm{Zn}}-\mathrm{ZnO}$ was reduced to $3.23 \mathrm{eV}$, which is smaller than those of $\mathrm{ZnO} \mathrm{ML}$ and $\mathrm{Y}-\mathrm{ZnO}$. Chemical bonds can be formed between a zinc atom and three adjacent oxygen atoms, so the $\mathrm{V}_{\mathrm{Zn}}$ induced holes provided by three surrounding $\mathrm{O}$ atoms. The increase in hole concentration hindered the transition of electrons and the recombination of $\mathrm{e}^{-}$and $\mathrm{h}^{+}$. In addition, the position of the Fermi level in $\mathrm{Y}-\mathrm{V}_{\mathrm{Zn}}-\mathrm{ZnO}$ was substantially consistent with that of $\mathrm{ZnO} M L$, which was located near the VBM. From Figure 6b, the $\mathrm{VBM}$ of $\mathrm{Y}-\mathrm{V}_{\mathrm{O}}-\mathrm{ZnO}$ was situated at the $\mathrm{G}$ point, whereas the $\mathrm{CBM}$ was located between the $\mathrm{Z}$ and $\mathrm{H}$ points. Thus, $\mathrm{Y}-\mathrm{V}_{\mathrm{O}}-\mathrm{ZnO}$ is an indirect bandgap semiconductor. The bandgap of $\mathrm{Y}-\mathrm{V}_{\mathrm{O}}-\mathrm{ZnO}(2.24 \mathrm{eV})$ was smaller than that of $\mathrm{Y}-\mathrm{V}_{\mathrm{Zn}}-\mathrm{ZnO}$. The Fermi level of $\mathrm{Y}-\mathrm{V}_{\mathrm{O}}-\mathrm{ZnO}$ lay near the $\mathrm{CBM}$, which produced typical n-type metallic characteristics [23]. This means that shallow donor states were created near the CBM, thus leading to an increase in carrier concentration. Besides this, some new impurity levels were found near the CBM. The appearance of the impurity levels indicates that electrons were introduced, which is conducive to the separation of electron-hole pairs when the incident light is irradiated.
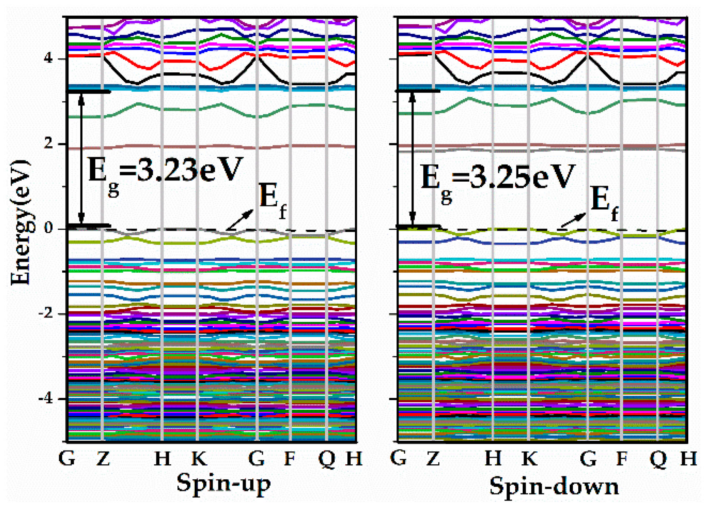

(a)
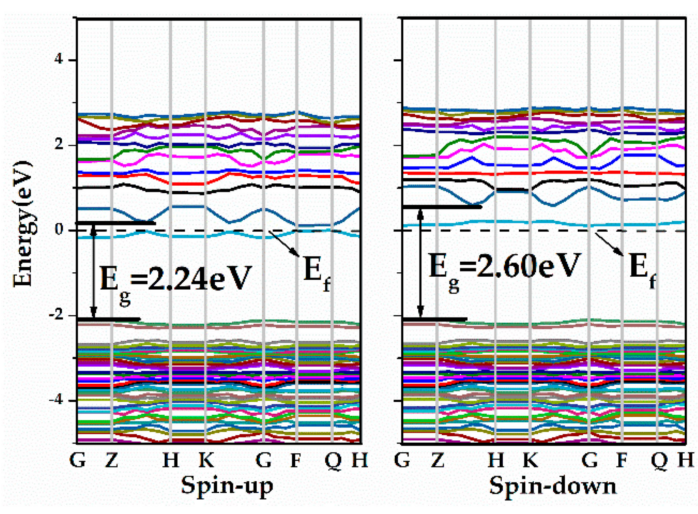

(b)

Figure 6. The band structures of (a) $\mathrm{Y}-\mathrm{V}_{\mathrm{Zn}}-\mathrm{ZnO}$, (b) $\mathrm{Y}-\mathrm{V}_{\mathrm{O}}-\mathrm{ZnO}$.

Figure 7 shows the TDOS and PDOS of ZnO MLs with $\mathrm{Y}$ and vacancy. Figure 7a shows that for $\mathrm{Y}-\mathrm{V}_{\mathrm{Zn}}-\mathrm{ZnO}, \mathrm{Y}-4 \mathrm{~d}$ states mainly acted at $2.00 \mathrm{eV}, 3.40 \mathrm{eV}$, and $4.40 \mathrm{eV}$. Given the appearance of $\mathrm{V}_{\mathrm{Zn}}$, the localization of $\mathrm{O}-2 \mathrm{p}$ states was weakened and the upper portion of the VB became 
diffuse. The incorporated $\mathrm{Y}$ atoms would have a stronger interaction with the $\mathrm{O}$ atoms, and orbital hybridization occurred near $2.0 \mathrm{eV}$ between $\mathrm{O}-2 \mathrm{p}$ states and $\mathrm{Y}-4 \mathrm{~d}$ states. Then, the impurity levels appeared. The spin-up and spin-down components of the $\mathrm{Y}-\mathrm{V}_{\mathrm{Zn}}-\mathrm{ZnO}$ DOS were almost symmetrical, indicating that the slight spin-polarization mainly came from the $2 \mathrm{p}$ electrons of $\mathrm{O}$ atoms. Figure $7 \mathrm{~b}$ clearly shows that for $\mathrm{Y}-\mathrm{V}_{\mathrm{O}}-\mathrm{ZnO}, \mathrm{Y}-4 \mathrm{~d}$ states mainly acted at $2.70 \mathrm{eV}$, whereas $\mathrm{Y}-5 \mathrm{~s}$ states mainly affected the DOS at $-2.90 \mathrm{eV}$ and $0 \mathrm{eV}$. The peak of the $\mathrm{O}-2 \mathrm{p}$ states moved to the lower energy region of $-2.90 \mathrm{eV}$, which caused the movement of VBM. At the same time, the localization of the $\mathrm{Zn}-3 \mathrm{~d}$ and O-2p states in VB became weak when $\mathrm{V}_{\mathrm{O}}$ was in $\mathrm{ZnO} \mathrm{ML}$. The orbital hybridization occurred at $-2.90 \mathrm{eV}$ among Y-5s, Y-4d, and O-2p states. Moreover, the CBM dropped from $4.01 \mathrm{eV}$ to $0.50 \mathrm{eV}$, which was induced by the action between $\mathrm{Y}-4 \mathrm{~d}$ and $\mathrm{Zn}-4 \mathrm{~s}$ states, resulting in a large reduction of the forbidden bandgap. The spin-up and spin-down components of the $\mathrm{Y}-\mathrm{V}_{\mathrm{O}}-\mathrm{ZnO}$ DOS were asymmetrical, suggesting that the spin-polarization mainly came from the $4 \mathrm{~d}$ and 5 s electrons of the $\mathrm{Y}$ atom. In summary, the forbidden band width of ZnO ML with $\mathrm{Y}$ and vacancy is reduced, and the introduced impurity level will act as a "springboard" for electrons to jump into the CB, which may result in a stronger optical absorption coefficient in the visible light region [60]. The value of DOS near the Fermi level increases because of $Y$ doping, which is also advantageous to the transition of electrons.

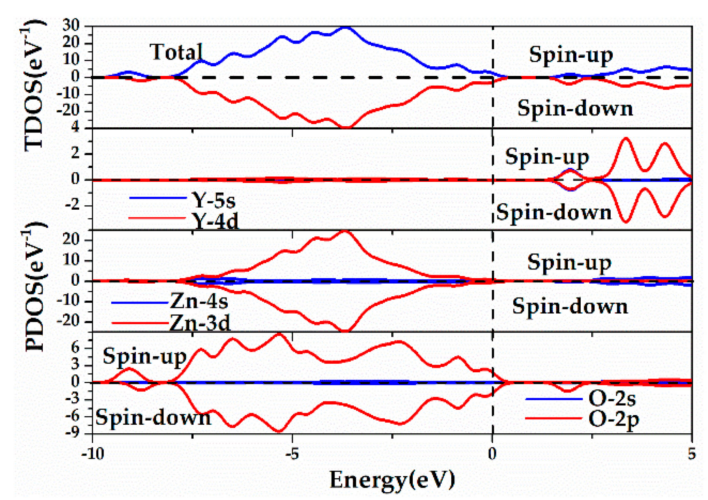

(a)

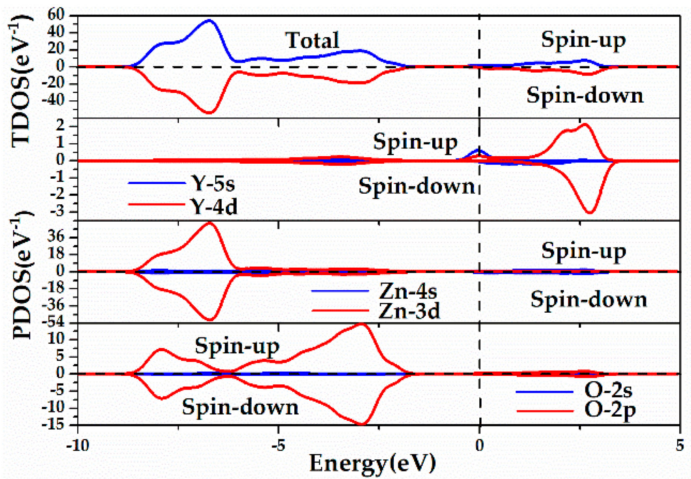

(b)

Figure 7. The calculated TDOS and PDOS of (a) $\mathrm{Y}-\mathrm{V}_{\mathrm{Zn}}-\mathrm{ZnO}$, (b) $\mathrm{Y}-\mathrm{V}_{\mathrm{O}}-\mathrm{ZnO}$.

\subsubsection{Population Analysis and Charge Density Difference}

To understand the bonding between atoms, the Mulliken charges for ZnO ML were calculated. Table 2 shows the gains and losses of electrons of ZnO ML with and without $Y$ or vacancy. The charge in $\mathrm{ZnO}$ ML doping systems was redistributed: $\mathrm{Y}$ and $\mathrm{Zn}$ atoms lost electrons, and the $\mathrm{O}$ atom obtained electrons. Hence, the $\mathrm{Y}$ atom incorporation will undergo a negative charge transfer with the adjacent $\mathrm{Zn}$ and $\mathrm{O}$ atoms. In addition, the charge change of $\mathrm{Zn}(1.07 \mathrm{e}$ and $1.03 \mathrm{e})$ in $\mathrm{V}_{\mathrm{Zn}}-\mathrm{ZnO}\left(\mathrm{Y}-\mathrm{V}_{\mathrm{Zn}}-\mathrm{ZnO}\right)$ was slightly greater than that $(0.98$ e and $0.84 \mathrm{e})$ in $\mathrm{V}_{\mathrm{O}}-\mathrm{ZnO}\left(\mathrm{Y}-\mathrm{V}_{\mathrm{O}}-\mathrm{ZnO}\right)$, indicating that the covalent strength of the $\mathrm{Zn}-\mathrm{O}$ bond in $\mathrm{V}_{\mathrm{Zn}}-\mathrm{ZnO}\left(\mathrm{Y}-\mathrm{V}_{\mathrm{Zn}}-\mathrm{ZnO}\right)$ was stronger than that in $\mathrm{V}_{\mathrm{O}}-\mathrm{ZnO}\left(\mathrm{Y}-\mathrm{V}_{\mathrm{O}}-\mathrm{ZnO}\right)$. For Y-doped ZnO ML with vacancy, the charge change of $Y(1.58$ e and $1.01 \mathrm{e})$ in $\mathrm{Y}-\mathrm{V}_{\mathrm{Zn}}-\mathrm{ZnO}\left(\mathrm{Y}-\mathrm{V}_{\mathrm{O}}-\mathrm{ZnO}\right)$ was larger than that of $\mathrm{Zn}(1.03$ e and $0.84 \mathrm{e})$, indicating that the $\mathrm{Y}-\mathrm{O}$ bond in $\mathrm{Y}-\mathrm{V}_{\mathrm{Zn}}-\mathrm{ZnO}\left(\mathrm{Y}-\mathrm{V}_{\mathrm{O}}-\mathrm{ZnO}\right)$ has a stronger covalent bond strength than $\mathrm{Zn}-\mathrm{O}$ in $\mathrm{Y}-\mathrm{V}_{\mathrm{Zn}}-\mathrm{ZnO}\left(\mathrm{Y}-\mathrm{V}_{\mathrm{O}}-\mathrm{ZnO}\right)$.

Table 3 shows the chemical bond lengths and bond populations of Y-doped ZnO MLs with and without vacancy. The bonding population indicates the degree of overlap of the two bonded atomic electron clouds, which can be used to obtain the properties of chemical bonds. The bond length of the Y-O bond revealed a linear relationship with the corresponding overlap population [61]. Table 3 shows that the degree of overlap of the electron cloud was inversely proportional to the bond length. The bond length of $\mathrm{Y}-\mathrm{O}$ was larger than that of $\mathrm{Zn}-\mathrm{O}(1.895 \AA)$, because the radius of $\mathrm{Y}^{3+}(0.09 \mathrm{~nm})$ is larger than that of $\mathrm{Zn}^{2+}(0.074 \mathrm{~nm})$. In addition, the $\mathrm{Y}-\mathrm{O}$ bond length of $\mathrm{Y}-\mathrm{V}_{\mathrm{Zn}}-\mathrm{ZnO}$ was shorter than that of $\mathrm{Y}-\mathrm{V}_{\mathrm{O}}-\mathrm{ZnO}$, which indicates that the $\mathrm{Zn}$ and $\mathrm{Y}$ electron clouds were overlapping. Therefore, the transfer 
of electrons is more difficult for $\mathrm{Y}-\mathrm{V}_{\mathrm{O}}-\mathrm{ZnO}$. The bond population of $\mathrm{Y}-\mathrm{O}$ bond for $\mathrm{Y}-\mathrm{V}_{\mathrm{Zn}}-\mathrm{ZnO}$ was the largest, indicating the strongest overlap of electron clouds. Vacancy had little effect on the Y-O bond population of $\mathrm{Y}-\mathrm{V}_{\mathrm{O}}-\mathrm{ZnO}$. In addition, the $\mathrm{Zn}-\mathrm{O}$ bond lengths in $\mathrm{Y}-\mathrm{ZnO}, \mathrm{Y}-\mathrm{V}_{\mathrm{Zn}}-\mathrm{ZnO}$, and $\mathrm{Y}-\mathrm{V}_{\mathrm{O}}-\mathrm{ZnO}$ were slightly larger than that in $\mathrm{ZnO} \mathrm{ML}$, but the bond population of $\mathrm{Zn}-\mathrm{O}$ in $\mathrm{Y}-\mathrm{ZnO}$, and $\mathrm{Y}-\mathrm{V}_{\mathrm{Zn}}-\mathrm{ZnO}$ was slightly less than that in $\mathrm{ZnO} M L$, indicating that the $\mathrm{Zn}-\mathrm{O}$ bond in $\mathrm{Y}-\mathrm{ZnO}$ and $\mathrm{Y}-\mathrm{V}_{\mathrm{Zn}}-\mathrm{ZnO}$ is more ionic than that in $\mathrm{ZnO}$ ML. The bond populations of $\mathrm{Zn}-\mathrm{O}$ and $\mathrm{Y}-\mathrm{O}$ in $\mathrm{Y}-\mathrm{ZnO}$ were the same, indicating that the ionic strength of the $\mathrm{Zn}-\mathrm{O}$ bond is similar to that of the $\mathrm{Y}-\mathrm{O}$ bond. The $\mathrm{Zn}-\mathrm{O}$ bond in $\mathrm{Y}-\mathrm{V}_{\mathrm{Zn}}-\mathrm{ZnO}$ was more ionic than the $\mathrm{Y}-\mathrm{O}$ bond, but $\mathrm{Y}-\mathrm{V}_{\mathrm{O}}-\mathrm{ZnO}$ showed the opposite trend. The difference is due to the vacancy.

Table 2. The atomic populations (Mulliken charge) of $\mathrm{ZnO} M L$ with $\mathrm{Y}$, vacancy $\left(\mathrm{V}_{\mathrm{Zn}}, \mathrm{V}_{\mathrm{O}}\right)$, and $\mathrm{ZnO}$ ML with $Y$ and vacancy $\left(V_{Z n}, V_{O}\right)$.

\begin{tabular}{|c|c|c|c|c|c|c|}
\hline \multirow{2}{*}{$\begin{array}{l}\text { Doping } \\
\text { System }\end{array}$} & \multirow{2}{*}{$\begin{array}{l}\text { Atomic } \\
\text { Species }\end{array}$} & \multicolumn{3}{|c|}{ Mulliken Charge (e) } & \multirow{2}{*}{$\begin{array}{c}\text { Total } \\
\text { Charge (e) }\end{array}$} & \multirow{2}{*}{$\begin{array}{c}\text { Charge } \\
\text { Change (e) }\end{array}$} \\
\hline & & $\mathrm{s}$ & $\mathrm{p}$ & $\mathrm{d}$ & & \\
\hline \multirow{3}{*}{$\mathrm{Y}-\mathrm{ZnO}$} & $\mathrm{Zn}$ & 0.53 & 0.50 & 9.97 & 11.00 & 1.00 \\
\hline & $\mathrm{O}$ & 1.84 & 5.14 & 0.00 & 6.99 & -0.99 \\
\hline & $\mathrm{Y}$ & 0.58 & 0.19 & 1.10 & 1.86 & 1.14 \\
\hline \multirow{2}{*}{$\mathrm{V}_{\mathrm{Zn}}-\mathrm{ZnO}$} & $\mathrm{Zn}$ & 0.49 & 0.48 & 9.97 & 10.93 & 1.07 \\
\hline & $\mathrm{O}$ & 1.85 & 5.15 & 0.00 & 7.00 & -1.00 \\
\hline \multirow{2}{*}{$\mathrm{V}_{\mathrm{O}}-\mathrm{ZnO}$} & $\mathrm{Zn}$ & 0.53 & 0.52 & 9.98 & 11.02 & 0.98 \\
\hline & $\mathrm{O}$ & 1.84 & 5.20 & 0.00 & 7.04 & -1.04 \\
\hline \multirow{3}{*}{$\mathrm{Y}-\mathrm{V}_{\mathrm{Zn}}-\mathrm{ZnO}$} & $\mathrm{Zn}$ & 0.51 & 0.49 & 9.97 & 10.97 & 1.03 \\
\hline & $\mathrm{O}$ & 1.85 & 5.16 & 0.00 & 7.01 & -1.01 \\
\hline & $\mathrm{Y}$ & 0.26 & 0.09 & 1.06 & 1.42 & 1.58 \\
\hline \multirow{3}{*}{$\mathrm{Y}-\mathrm{V}_{\mathrm{O}}-\mathrm{ZnO}$} & $\mathrm{Zn}$ & 0.65 & 0.55 & 9.96 & 11.16 & 0.84 \\
\hline & $\mathrm{O}$ & 1.86 & 5.05 & 0.00 & 6.91 & -0.91 \\
\hline & Y & 0.56 & 0.12 & 1.31 & 1.99 & 1.01 \\
\hline
\end{tabular}

Table 3. Bond lengths (LB) and bond populations (PB) of Y-doped ZnO ML and Y-doped ZnO ML with $\mathrm{V}_{\mathrm{Zn}}$ or $\mathrm{V}_{\mathrm{O}}$.

\begin{tabular}{ccccc}
\hline \multirow{2}{*}{ Model } & \multicolumn{2}{c}{ Y-O } & \multicolumn{2}{c}{ Zn-O } \\
\cline { 2 - 5 } & LB (̊) & PB & LB & PB \\
\hline $\mathrm{ZnO} \mathrm{ML}$ & - & - & 1.895 & 0.43 \\
\hline $\mathrm{Y}-\mathrm{ZnO}$ & 2.225 & 0.42 & 1.905 & 0.42 \\
\hline $\mathrm{Y}-\mathrm{V}_{\mathrm{Zn}}-\mathrm{ZnO}$ & 2.204 & 0.50 & 1.900 & 0.42 \\
\hline $\mathrm{Y}-\mathrm{V}_{\mathrm{O}}-\mathrm{ZnO}$ & 2.230 & 0.41 & 1.905 & 0.43 \\
\hline
\end{tabular}

Figure 8 depicts the charge density differences of $\mathrm{ZnO} M L$ and Y-doped $\mathrm{ZnO}$ ML with or without vacancy. As shown in Figure 8b, the charge density distribution changed obviously with $\mathrm{Y}$ doping. The electron densities around $\mathrm{Zn}^{2+}(1.00 \mathrm{e})$ and $\mathrm{Y}^{3+}(1.14 \mathrm{e})$ ions are different, which can be seen from the Mulliken charge in Table 2. The incorporation of $Y$ and vacancy into a crystal induced modifications of the electron density distribution in the space between crystal lattice ions, as provided in Figure $8 c, d$ [61]. This result indicates that the covalent bond characteristic between $Y$ and adjacent $O$ atoms in $\mathrm{Y}-\mathrm{V}_{\mathrm{Zn}}-\mathrm{ZnO}$ was stronger than that in $\mathrm{Y}-\mathrm{ZnO}$ and $\mathrm{Y}-\mathrm{V}_{\mathrm{O}}-\mathrm{ZnO}$ because of the overlap of electron clouds and a strong interaction. In addition, the electron cloud overlap of $\mathrm{Zn}-\mathrm{O}$ bonds near the $\mathrm{V}_{\mathrm{Zn}}$ in Figure $8 \mathrm{c}$ was significantly greater than that near the $\mathrm{V}_{\mathrm{O}}$ in Figure $8 \mathrm{~d}$. The $\mathrm{Zn}$-O bond near the $\mathrm{V}_{\mathrm{Zn}}$ 
was more covalent, indicating that the electron transfer between the $\mathrm{Zn}$ atom and the adjacent $\mathrm{O}$ atom near the $\mathrm{V}_{\mathrm{Zn}}$ was less than that near the $\mathrm{V}_{\mathrm{O}}$.

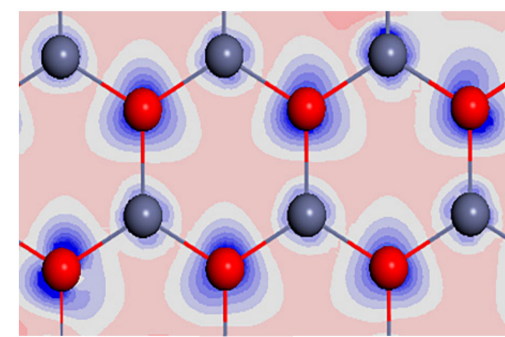

(a)

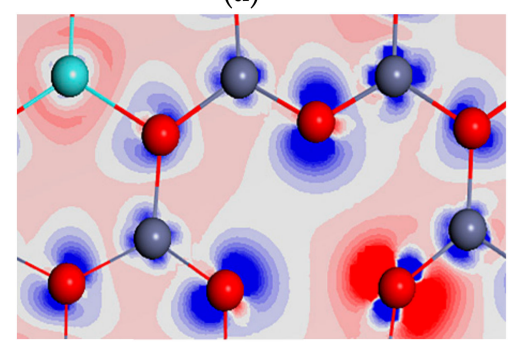

(c)

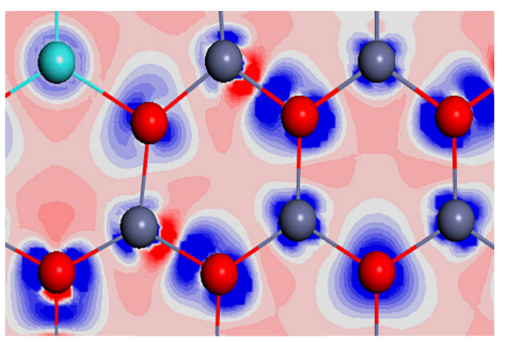

(b)

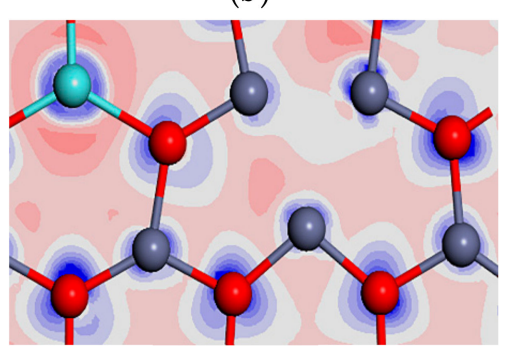

(d) accumulation depletion

Figure 8. The charge density differences of (a) $\mathrm{ZnO} \mathrm{ML}$, (b) $\mathrm{Y}-\mathrm{ZnO}$, (c) $\mathrm{Y}-\mathrm{V}_{\mathrm{Zn}}-\mathrm{ZnO}$, and (d) $\mathrm{Y}-\mathrm{V}_{\mathrm{O}}-\mathrm{ZnO}$. Electron accumulation and electron depletion are shown in blue and red, respectively, and the areas with minimal change in the electron density are shown in white.

\subsection{Optical Properties}

To better understand the application of $\mathrm{Y}-\mathrm{ZnO}, \mathrm{V}_{\mathrm{Zn}}-\mathrm{ZnO}, \mathrm{V}_{\mathrm{O}}-\mathrm{ZnO}, \mathrm{Y}-\mathrm{V}_{\mathrm{Zn}}-\mathrm{ZnO}$, and $\mathrm{Y}-\mathrm{V}_{\mathrm{O}}-\mathrm{ZnO}$ in nanodevices, the optical properties should be calculated. In this work, the optical properties of $\mathrm{ZnO} \mathrm{ML}$ with impurity or defect were obtained by the GGA+U method. In the linear response range, the macroscopic optical response function of the solid is described by the complex dielectric function of light $\varepsilon(\omega)=\varepsilon_{1}(\omega)+i \varepsilon_{2}(\omega)$. The dielectric function $\varepsilon(\omega)$ characterizes the linear response of the materials to electromagnetic radiation. The imaginary part $\varepsilon_{2}(\omega)$ of the dielectric function is directly related to optical absorption coefficient, which can be calculated from the matrix element between the electronic wave functions of the occupied states and the unoccupied states according to the selection rule of the electronic transition [62]. The imaginary part $\varepsilon_{2}(\omega)$ is expressed as follows [43]:

$$
\varepsilon_{2}(\omega)=\frac{2 e^{2} \pi}{\Omega \varepsilon_{0}} \sum_{k, v, c}\left|\varphi_{k}^{c}\right| u \cdot r\left|\varphi_{k}^{v}\right|^{2} \delta\left(E_{k}^{c}-E_{k}^{v}-E\right),
$$

where $\omega$ is the frequency of incident photons; $\Omega$ is the unit cell volume; $\varepsilon_{0}$ is the permittivity in free space; $k$ is the reciprocal lattice vector; $v$ and $c$ stand for the VB and CB, respectively; $u$ and $r$ are the vector defining polarization of the incident electric field and the position vector; $\varphi_{k}^{c}$ and $\varphi_{k}^{v}$ are the wave functions of CB and VB, respectively [16].

The absorption coefficient $\alpha(\omega)$ describes the percentage of light intensity attenuation at the unit distance of light wave propagation, which can be obtained from $\varepsilon_{1}(\omega)$ and $\varepsilon_{2}(\omega)$, as follows [63]:

$$
\alpha(\omega)=\sqrt{2} \omega\left[\sqrt{\varepsilon_{1}^{2}(\omega)+\varepsilon_{2}^{2}(\omega)}-\varepsilon_{1}(\omega)\right]^{1 / 2} .
$$

During the calculation of the imaginary part of the dielectric function and the absorption coefficient, the incident radiation is linearly polarized along the (100) direction. The energy range of the visible spectrum is $1.63-3.10 \mathrm{eV}$, and the corresponding wavelength is $760-400 \mathrm{~nm}$. 
Figure 9 depicts the results of imaginary part and the absorption coefficient of Y-doped ZnO MLs with vacancy. The calculation results of the pure $\mathrm{ZnO} M L$ and $\mathrm{ZnO}$ MLs with $\mathrm{Y}$ or vacancy are also shown for comparison. The peak was determined by the electron transition, which followed the selection rules. Figure 9a shows two distinct peaks in the dielectric function of $\mathrm{ZnO} M L$, which are located at $4.70 \mathrm{eV}$ and $7.70 \mathrm{eV}$, respectively. For Y-ZnO, the position of the absorption peak gradually shifted toward the higher energy region with $Y$ doping, which is known as a blue-shift. A new peak appeared near $0.75 \mathrm{eV}$, which was mainly attributed to $\mathrm{Y}$ doping. For $\mathrm{V}_{\mathrm{Zn}}-\mathrm{ZnO}$, one main peak was shown at $4.70 \mathrm{eV}$ and moved to $5.10 \mathrm{eV}$, which is called a blue-shift. For $\mathrm{V}_{\mathrm{O}}-\mathrm{ZnO}$, the main peak shifted to lower energy with the existence of $\mathrm{V}_{\mathrm{O}}$, which is known as a red-shift. For $\mathrm{Y}-\mathrm{V}_{\mathrm{Zn}}-\mathrm{ZnO}$, three main peaks were observed, and they exhibited a blue-shift. For $\mathrm{Y}-\mathrm{V}_{\mathrm{O}}-\mathrm{ZnO}$, three main peaks showed a red-shift, and the values of the main peaks are larger than those of $\mathrm{ZnO} \mathrm{ML}, \mathrm{Y}-\mathrm{ZnO}, \mathrm{V}_{\mathrm{Zn}}-\mathrm{ZnO}, \mathrm{V}_{\mathrm{O}}-\mathrm{ZnO}$, and $\mathrm{Y}-\mathrm{V}_{\mathrm{Zn}}-\mathrm{ZnO}$ in the low energy region $(<7.0 \mathrm{eV})$. In Figure $9 \mathrm{~b}$, the peak of the absorption curve has a similar relative position to the imaginary part of the dielectric function. The absorption edge of $\mathrm{ZnO} \mathrm{ML}$ was located at $4.0 \mathrm{eV}$, which is approximately equal to the bandgap of $\mathrm{ZnO}$ ML. For Y-ZnO, a new absorption peak emerged at $1.20 \mathrm{eV}$ because $\mathrm{Y}$ doping induced impurity levels near the Fermi level. The formation of donor centers and the incorporation of $\mathrm{Y}^{3+}$ resulted in the formation of shallow levels or a sub band inside the forbidden band, resulting in a blue-shift approximately $4.90 \mathrm{eV}$ in the absorption spectrum of $\mathrm{Y}-\mathrm{ZnO}$ [25]. For vacancy, these results clearly show that the optical absorption coefficient of the $\mathrm{ZnO} M L$ is considerably affected by the presence of vacancy. For $\mathrm{V}_{\mathrm{Zn}}-\mathrm{ZnO}$, although the presence of $\mathrm{V}_{\mathrm{Zn}}$ slightly enhanced the optical absorption properties of the $\mathrm{ZnO} M L$ in the visible light region (VIS), the optical absorption coefficient in ultraviolet (UV) region decreased at the same time. For $\mathrm{V}_{\mathrm{O}}-\mathrm{ZnO}$, the O-deficient $\mathrm{ML}$ showed an optical absorption band from $1.20 \mathrm{eV}$ to $4.80 \mathrm{eV}$ and the main optical absorption peak at $4.80 \mathrm{eV}$. The optical absorption coefficients in VIS and UV regions increased greatly, which indicates that the absorption coefficients in VIS and UV regions are enhanced by the presence of oxygen vacancy. For $\mathrm{Y}-\mathrm{V}_{\mathrm{Zn}}-\mathrm{ZnO}$, in the range of $0-1.50 \mathrm{eV}$, the absorption coefficient was almost 0 , which is smaller than that of $\mathrm{Y}-\mathrm{ZnO}$. The absorption edge of $\mathrm{Y}-\mathrm{V}_{\mathrm{Zn}}-\mathrm{ZnO}$ was red-shifted to the lower energy region near $2.0 \mathrm{eV}$, which is close to the energy difference from the VBM to the impurity levels. Given the presence of impurity levels, electrons were more likely to be excited from the VB to impurity levels and $\mathrm{CB}$, which reduced the required electron energy, resulting in a red-shift at the edge of the absorption spectrum. The absorption coefficient of $\mathrm{Y}^{-\mathrm{V}_{\mathrm{Zn}}}-\mathrm{ZnO}$ was larger than those of $\mathrm{Y}-\mathrm{ZnO}$ and $\mathrm{V}_{\mathrm{Zn}}-\mathrm{ZnO}$ in the VIS region. No new absorption peaks appeared in the visible light region for $\mathrm{Y}-\mathrm{V}_{\mathrm{Zn}}-\mathrm{ZnO}$. The absorption coefficients of $\mathrm{Y}-\mathrm{V}_{\mathrm{Zn}}-\mathrm{ZnO}$ and $\mathrm{Y}-\mathrm{V}_{\mathrm{O}}-\mathrm{ZnO}$ were improved in the range from $2.0 \mathrm{eV}$ to $4.0 \mathrm{eV}$, and the improvement is beneficial for the utilization of visible light. Given the appearance of $\mathrm{V}_{\mathrm{Zn}}$, the interactions between $\mathrm{Y}$ and $\mathrm{O}$ atoms were enhanced, the number of free electrons in the system was reduced, and the electron transition was limited to a certain extent. Moreover, $\mathrm{Y}-\mathrm{V}_{\mathrm{O}}-\mathrm{ZnO}$ possessed the highest absorption coefficient in the VIS region compared with other doping systems, including $\mathrm{Y}-\mathrm{V}_{\mathrm{Zn}}-\mathrm{ZnO}$ and $\mathrm{V}_{\mathrm{O}}-\mathrm{ZnO}$. This is because the forbidden bandgap of $\mathrm{Y}-\mathrm{V}_{\mathrm{O}}-\mathrm{ZnO}$ decreased to $2.24 \mathrm{eV}$, and the Fermi level was located close to the CBM, which led to abundant electrons jumping from the VB to $C B$. In particular, the existence of $V_{O}$ enhanced the interaction between $\mathrm{Y}$ and $\mathrm{O}$ atoms, thus decreasing the number of free electrons in the system and greatly improving the photocatalytic properties of $\mathrm{ZnO} \mathrm{ML}$. In general, compared with other doping systems, $\mathrm{Y}-\mathrm{V}_{\mathrm{O}}-\mathrm{ZnO}$ has the highest absorption coefficient and the strongest photocatalysis in the visible region. 


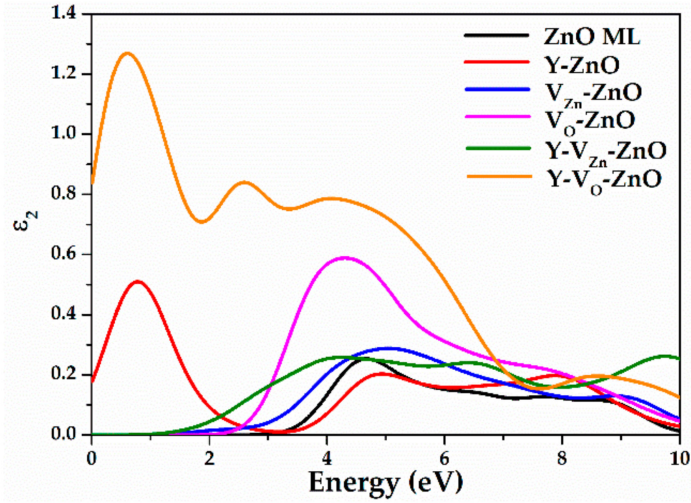

(a)

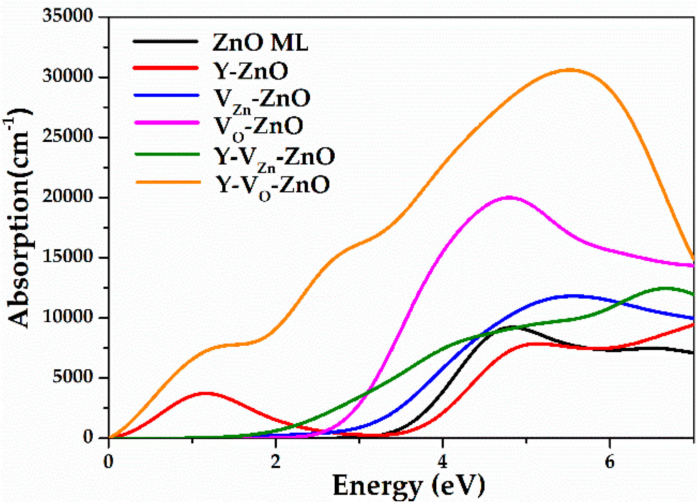

(b)

Figure 9. (a) The imaginary part of dielectric function and (b) the absorption coefficient of $\mathrm{ZnO} M L$, $\mathrm{Y}-\mathrm{ZnO}, \mathrm{V}_{\mathrm{Zn}}-\mathrm{ZnO}, \mathrm{V}_{\mathrm{O}}-\mathrm{ZnO}, \mathrm{Y}-\mathrm{V}_{\mathrm{Zn}}-\mathrm{ZnO}$, and $\mathrm{Y}-\mathrm{V}_{\mathrm{O}}-\mathrm{ZnO}$.

\subsection{Photocatalytic Reaction Mechanism and Installation Scheme of Photocatalytic Oxidation}

Figure 10 shows the mechanism of the electron-hole pairs transfer in $\mathrm{Y}-\mathrm{V}_{\mathrm{O}}-\mathrm{ZnO}$, leading to the catalytic degradation of pollutants under visible light irradiation. When $\mathrm{Y}-\mathrm{V}_{\mathrm{O}}-\mathrm{ZnO}$ is illuminated by sunlight, the electrons in the VB are excited by photons to jump to the $\mathrm{CB}$, and the corresponding holes are retained in the VB. Photo-generated electrons and holes are separated by an electric field and move to the surface of semiconductor particles. The photo-generated pores have strong oxidizing properties and can oxidize substances adsorbed on the surface or solution of the semiconductor [2].

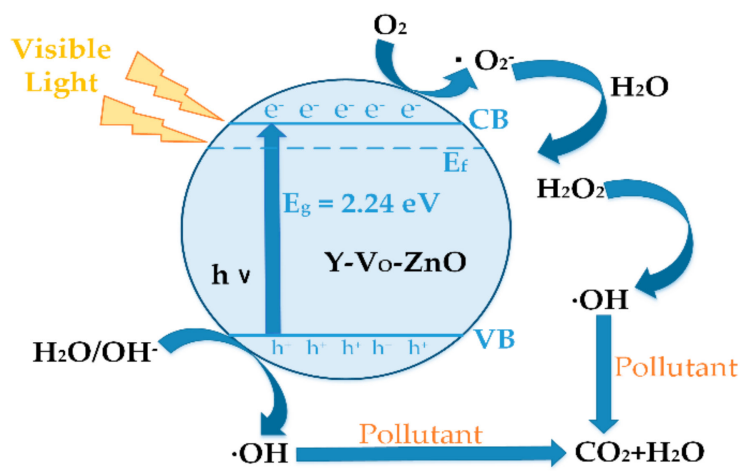

Figure 10. Photocatalytic mechanism of $\mathrm{Y}-\mathrm{V}_{\mathrm{O}}-\mathrm{ZnO}$ nanocatalyst.

During the photocatalytic process, the hole in the VB diffuses to the photocatalyst surface and oxidises with $\mathrm{H}_{2} \mathrm{O} / \mathrm{OH}^{-}$to form hydroxyl radicals $(\cdot \mathrm{OH})$. The electrons in the $\mathrm{CB}$ move to the surface of the catalyst and react with $\mathrm{O}_{2}$ to produce superoxide radical anions $\left(\cdot \mathrm{O}_{2}^{-}\right)$, which can be utilized as species for the degradation of organic pollutants by oxidation [64]. The surface reactions are given in Equations (4)-(9):

$$
\begin{gathered}
\mathrm{Y}-\mathrm{V}_{\mathrm{O}}-\mathrm{ZnO}+\mathrm{h} v(\text { VIS light }) \rightarrow \mathrm{h}^{+}+\mathrm{e}^{-}, \\
\mathrm{H}_{2} \mathrm{O} / \mathrm{OH}^{-}+\mathrm{h}^{+} \rightarrow \cdot \mathrm{OH}, \\
\mathrm{O}_{2}+\mathrm{e}^{-} \rightarrow \mathrm{O}_{-2} \\
\mathrm{O}_{2}^{-}+\mathrm{H}_{2} \mathrm{O} \rightarrow \mathrm{H}_{2} \mathrm{O}_{2}+\mathrm{O}_{2} \\
\mathrm{H}_{2} \mathrm{O}_{2}+\mathrm{e}^{-} \rightarrow \cdot \mathrm{OH}, \\
\mathrm{h}^{+}+\mathrm{O}_{2}^{-}+\mathrm{OH}+\text { Pollutant } \rightarrow \mathrm{H}_{2} \mathrm{O}+\mathrm{CO}_{2} \uparrow
\end{gathered}
$$


From the above photocatalytic reaction processes, the photocatalytic property of $\mathrm{Y}-\mathrm{V}_{\mathrm{O}}-\mathrm{ZnO}$ was improved compared with the original $\mathrm{ZnO}$ ML. The doping of $Y$ and vacancy can effectively promote the separation of electron-hole pairs, thus prolonging carrier lifetime. More carriers jump to the $\mathrm{ZnO}$ ML surface and participate in the photocatalytic reaction under visible light irradiation, which improves the redox reaction efficiency. Finally, the organic pollutants are decomposed into non-toxic $\mathrm{H}_{2} \mathrm{O}$ and $\mathrm{CO}_{2}$, achieving the goal of pollutant degradation.

The photocatalytic oxidation of azo dye wastewater was performed in the equipment shown in Figure 11. The main component of the system was the flow reactor (Trojan Technologies, London, ON, Canada) with a refill covered with a titania-silica coating [65]. The solar reactor included one UV transparent glass tube as a receiver [66]. The photoactive refill was adhered to the inner walls of the reactor. The refill was composed of a thin $\mathrm{Y}-\mathrm{V}_{\mathrm{O}}-\mathrm{ZnO}$ layer mixed with a water solution of silicone binder. Before photocatalysis, the reactor was washed with excess immobilized photocatalyst to ensure that only a thin layer of the photocatalyst remained on the fabric. The azo dye wastewater was pumped from the feed tank into the reactor and circulated in the reactor. Samples were extracted termly for analysis until the azo dye wastewater was decomposed into a colorless, non-toxic liquid.

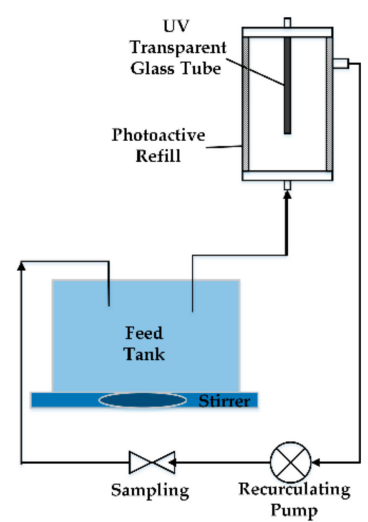

Figure 11. Schematic of solar catalyzed oxidation unit.

\section{Conclusions}

In summary, we explored crystal structure, structural stability, electronic structure, and optical properties of $\mathrm{Y}$-doped $\mathrm{ZnO} \mathrm{ML}$ with $\mathrm{V}_{\mathrm{Zn}}$ or $\mathrm{V}_{\mathrm{O}}$ by first-principles density functional theory. For comparison, a first-principles study of pure $\mathrm{ZnO} M L$ and $\mathrm{ZnO}$ MLs with $\mathrm{Y}$ or vacancy was calculated. The calculation results showed that the maximum formation energy value of $\mathrm{Y}-\mathrm{ZnO}$ is $-0.188 \mathrm{eV}$. The formation energies of $\mathrm{ZnO}$ MLs with vacancy and $\mathrm{ZnO}$ MLs with $\mathrm{Y}$ and vacancy $\left(\mathrm{V}_{\mathrm{Zn}}\right.$, $\mathrm{V}_{\mathrm{O}}$ ) were positive, indicating that $\mathrm{ZnO}$ MLs with vacancy are unstable with or without $Y$. The bandgap of $\mathrm{ZnO}$ ML increased with the presence of Y. Meanwhile, impurity levels appeared near Fermi level in $\mathrm{Y}-\mathrm{ZnO}$, which was attributed to $\mathrm{Y}-4 \mathrm{~d}$ and $\mathrm{Zn}-4 \mathrm{~s}$ states. In addition, the bandgap of $\mathrm{Y}$-doped $\mathrm{ZnO}$ $\mathrm{ML}$ with vacancy was smaller than those of $\mathrm{ZnO} \mathrm{ML}, \mathrm{Y}-\mathrm{ZnO}$, and $\mathrm{V}_{\mathrm{O}}-\mathrm{ZnO}$, which suggests that the emission of Y-doped ZnO MLs with $\mathrm{V}_{\mathrm{Zn}}$ or $\mathrm{V}_{\mathrm{O}}$ would exhibit a red-shift from $4.03 \mathrm{eV}$ to $3.23 \mathrm{eV}, 2.24 \mathrm{eV}$, respectively. The impurity level could be induced by the doping of $\mathrm{Y}$ or $\mathrm{V}_{\mathrm{O}}$, which is advantageous for the electronic transition. Population analysis and charge density difference showed the change in the electrons and the bonding situation of $\mathrm{Zn}, \mathrm{O}$, and $\mathrm{Y}$ atoms in the $\mathrm{ZnO}$ monolayer doping systems. Moreover, the light absorptions of Y-doped ZnO MLs with vacancy were enhanced in the visible light region compared with that of the pristine $\mathrm{ZnO} M L$ and $\mathrm{ZnO} M L$ with one defect $\left(\mathrm{Y}, \mathrm{V}_{\mathrm{Zn}}\right.$, or $\left.\mathrm{V}_{\mathrm{O}}\right)$. In particular, the enhancement of the absorption coefficient of yttrium-doped ZnO ML in the VIS region became more pronounced with or without $V_{O}$. This work can provide some references for the application of $\mathrm{Y}-\mathrm{V}_{\mathrm{O}}-\mathrm{ZnO}$ in the photocatalytic field. 
Author Contributions: Q.W. performed the calculations, analyzed the results, and wrote the manuscript; P.W. designed the project, analyzed the results, and wrote the manuscript; Y.L., H.Y., J.C., L.G., Y.Y. and Z.Z. analyzed the results. All authors have read and agreed to the published version of the manuscript.

Funding: This work is supported by the National Natural Science Foundation of China (Grant No. 61474090) and the Key Research and Development Program of Shaanxi Province of China (Grant No. 2017ZDXM-GY-052).

Conflicts of Interest: The authors declare no conflict of interest.

\section{References}

1. Wang, C.L.; Sun, Z.X.; Zheng, Y.; Hu, Y.H. Recent progress in visible light photocatalytic conversion of carbon dioxide. J. Mater. Chem. A 2019, 7, 865-887. [CrossRef]

2. Zhang, F.B.; Wang, X.M.; Liu, H.N.; Liu, C.L.; Wan, Y.; Long, Y.Z.; Cai, Z.Y. Recent Advances and Applications of Semiconductor Photocatalytic Technology. Appl. Sci. 2019, 9, 2489. [CrossRef]

3. Sun, B.; Yang, X.P.; Zhao, D.; Zhang, L.Q. First-principles study of adsorption mechanism of $\mathrm{NH}_{3}$ on different $\mathrm{ZnO}$ surfaces on organics photocatalytic degradation purpose. Comput. Mater. Sci. 2018, 141, 133-140. [CrossRef]

4. Wang, J.J.; Yang, X.T.; Cao, J.R.; Wang, Y.; Li, Q.X. Computational study of the electronic, optical and photocatalytic properties of single-layer hexagonal zinc chalcogenides. Comput. Mater. Sci. 2018, 150, 432-438. [CrossRef]

5. Beura, R.; Thangadurai, P. Structural, optical and photocatalytic properties of graphene-ZnO nanocomposites for varied compositions. J. Phys. Chem. Solids 2017, 102, 168-177. [CrossRef]

6. Fu, S.Y.; Chen, J.R.; Han, H.S.; Wang, W.Z.; Shi, H.L.; Fu, J.L.; Jia, Y. ZnO@Au@Cu $\mathrm{O}_{2}$ nanotube arrays as efficient visible-light-driven photoelectrod. J. Alloys Compd. 2019, 799, 183-192. [CrossRef]

7. Fujishima, A.; Honda, K. Electrochemical Photolysis of Water at a Semiconductor Electrode. Nature 1972, 238, 37-38. [CrossRef] [PubMed]

8. Chen, S.F.; Liu, F.N.; Xu, M.Z.; Yan, J.F.; Zhang, F.C.; Zhao, W.; Zhang, Z.Y.; Deng, Z.H.; Yun, J.N.; Chen, R.Y.; et al. First-principles calculations and experimental investigation on $\mathrm{SnO}_{2} @ \mathrm{ZnO}$ heterojunction photocatalyst with enhanced photocatalytic performance. J. Colloid Interface Sci. 2019, 553, 613-621. [CrossRef]

9. Tu, N.; Bui, H.V.; Trung, D.Q.; Duong, A.T.; Thuy, D.M.; Nguyen, D.H.; Nguyen, K.T.; Huy, P.T. Surface oxygen vacancies of $\mathrm{ZnO}$ : A facile fabrication method and their contribution to the photoluminescence. J. Alloys Compd. 2019, 791, 722-729. [CrossRef]

10. Li, X.Y.; Liu, D.X.; Zhu, B.Y.; Wang, J.; Lang, J.H. Facile preparation of $\mathrm{ZnO} / \mathrm{Ag}_{2} \mathrm{CO}_{3}$ heterostructured nanorod arrays with improved photocatalytic activity. J. Phys. Chem. Solids 2019, 125, 96-102. [CrossRef]

11. Singh, G.; Kumar, S.; Singh, V.P.; Vaish, R. Transparent ZnO crystallized glass ceramics for photocatalytic and antibacterial applications. J. Appl. Phys. 2019, 125, 175102. [CrossRef]

12. Mohamed, W.S.; Abu-Diefb, A.M. Synthesis, characterization and photocatalysis enhancement of $\mathrm{Eu}_{2} \mathrm{O}_{3}-\mathrm{ZnO}$ mixed oxide nanoparticles. J. Phys. Chem. Solids 2018, 116, 375-385. [CrossRef]

13. Zhang, H.F.; Tao, Z.; Xu, W.G.; Lu, S.X.; Yuan, F. First-principles study of dopants and defects in S-doped $\mathrm{ZnO}$ and its effect on photocatalytic activity. Comput. Mater. Sci. 2012, 58, 119-124. [CrossRef]

14. Kumar, M.R.; Nagaswarupa, H.P.; Ravikumar, C.R.; Prashantha, S.C.; Nagabhushana, H.; Bhatt, A.S. Green engineered nano $\mathrm{MgO}$ and $\mathrm{ZnO}$ doped with $\mathrm{Sm}^{3+}$ : Synthesis and a comparison study on their characterization, PC activity and electrochemical properties. J. Phys. Chem. Solids 2019, 127, 127-139. [CrossRef]

15. Cheng, J.S.; Wang, P.; Hua, C.; Yang, Y.T.; Zhang, Z.Y. First principles investigations of the structural, electrical and optical properties of iron-doped zinc oxide $\left(\begin{array}{llll}0 & 0 & 0 & 1\end{array}\right)$ surfaces. Comput. Mater. Sci. 2018, 154, 435-441. [CrossRef]

16. Ma, Z.H.; Ren, F.Z.; Ming, X.L.; Long, Y.Q.; Volinsky, A.A. Cu-Doped ZnO Electronic Structure and Optical Properties Studied by First-Principles Calculations and Experiments. Materials 2019, 12, 196. [CrossRef]

17. El Hachimi, A.G.; NE, M.L.O.; El Yousfi, A.; Benyoussef, A.; El Kenz, A. Enhancing optical absorption in visible light of $\mathrm{ZnO}$ co-doped with europium and promethium by first-principles study through modified Becke and Johnson potential scheme. J. Rare Earths 2019, 37, 416-421. [CrossRef]

18. Jia, X.F.; Hou, Q.Y.; Xu, Z.C.; Qu, L.F. Effect of Ce doping on the magnetic and optical properties of ZnO by the first principle. J. Magn. Magn. Mater. 2018, 465, 128-135. [CrossRef] 
19. Sarfraz, M.; Ahmed, N.; Khizar, U.H.; Shahida, S.; Khan, M.A. Structural optical and magnetic properties of transition metal doped $\mathrm{ZnO}$ magnetic nanoparticles synthesized by sol-gel auto-combustion method. Mater. Sci. Pol. 2019, 29, 280-288. [CrossRef]

20. Sun, D.; Tan, C.L.; Tian, X.H.; Huang, Y.W. Comparative Study on ZnO Monolayer Doped with Al, Ga and in Atoms as Transparent Electrodes. Materials 2017, 10, 703. [CrossRef]

21. Ivanova, T.; Harizanova, A.; Koutzarova, T.; Vertruyen, B. Sol-gel derived ZnO:Y nanostructured films: Structural and optical study. Colloids Surf. A 2017, 532, 363-368. [CrossRef]

22. Bazta, O.; Urbieta, A.; Piqueras, J.; Fernandez, P.; Addou, M.; Calvino, J.J.; Hungria, A.B. Influence of yttrium doping on the structural, morphological and optical properties of nanostructured $\mathrm{ZnO}$ thin films grown by spray pyrolysis. Ceram. Int. 2019, 45, 6842-6852. [CrossRef]

23. Wang, P.; He, J.F.; Guo, L.X.; Yang, Y.T.; Zheng, S.K. The electronic structures and optical properties of yttrium-doped zinc oxide with zinc interstitial defects calculated by first-principles. Mater. Sci. Semicond. Process. 2015, 36, 36-42. [CrossRef]

24. Lahmer, M.A. The effect of doping with rare earth elements (Sc, Y, and La) on the stability, structural, electronic and photocatalytic properties of the O-terminated ZnO surface, A first-principles study. Appl. Surf. Sci. 2018, 457, 315-322. [CrossRef]

25. Qasim, A.K.; Jamil, L.A.; Chen, Q. Enhanced Photoelectrochemical Water Splitting of Hydrothermally-Grown $\mathrm{ZnO}$ and Yttrium-doped ZnO NR Arrays. IOP Conf. Ser. Mater. Sci. Eng.. 2018, 454, 012033. [CrossRef]

26. Hashmi, J.Z.; Siraj, K.; Naseem, S.; Shaukat, S. Dopant-induced modifications in structural and optical properties of $\mathrm{ZnO}$ thin films prepared by PLD. Mater. Res. Express 2016, 3, 096402. [CrossRef]

27. Bai, L.N.; Sun, H.M.; Lian, J.S.; Jiang, Q. Tunable UV Absorption and Mobility of Yttrium-Doped ZnO using First-Principles Calculations. Chin. Phys. Lett. 2012, 11, 117101. [CrossRef]

28. Tang, Y.W.; Zhou, H.; Zhang, K.; Ding, J.; Fan, T.X.; Zhang, D. Visible-light-active ZnO via oxygen vacancy manipulation for efficient formaldehyde photodegradation. Chem. Eng. J. 2015, 262, 260-267. [CrossRef]

29. Wang, Z.L.; Su, S.C.; Younas, M.; Ling, F.C.C.; Anwand, W.; Wagner, A. The Zn-vacancy related green luminescence and donor-acceptor pair emission in $\mathrm{ZnO}$ grown by pulsed laser deposition. RSC Adv. 2015, 5, 12530-12535. [CrossRef]

30. Lahmer, M.A. The effect of growth conditions and vacancies on the electronic, optical and photocatalytic properties of the ZnO (1010) surface. Mater. Chem. Phys. 2016, 182, 200-207. [CrossRef]

31. Bai, L.L.; Lin, Z.P.; Wen, M.R.; Dong, H.F.; Liu, Z.T.; Chen, S.S.; Wu, F.G. Vacancies inducing electronic and optical properties in 2D ZnO:Be/Mg. Physica B 2019, 555, 47-52. [CrossRef]

32. Catellani, A.; Ruini, A.; Calzolari, A. Optoelectronic properties and color chemistry of native point defects in Al:ZnO transparent conductive oxide. J. Mater. Chem. C 2015, 3, 8419-8424. [CrossRef]

33. Meng, Z.S.; Mo, X.M.; Cheng, X.; Zhou, Y.L.; Tao, X.M.; Ouyang, Y.F. Interactions between Er dopant and intrinsic point defects of ZnO: A first-principles study. Mater. Res. Express 2017, 4, 035903. [CrossRef]

34. Qu, L.F.; Hou, Q.Y.; Jia, X.F.; Xu, Z.C.; Zhao, C.W. Effects of Eu doping and O vacancy on the magnetic and optical properties of ZnO. Physica B 2018, 530, 133-141.

35. Li, W.L.; Hou, Q.Y.; Xu, Z.C.; Zhao, C.W. Study of point defect on the stability and magneto-optical properties of ZnO:Cu by first-principles. Mol. Phys. 2019, 117, 1858-1870. [CrossRef]

36. Li, C.; Hou, Q.Y. Effects of Y doping with point defects on the ferromagnetic properties of $\mathrm{ZnO}(0001)-\mathrm{Zn}$ polar surface. Appl. Surf. Sci. 2018, 459, 393-396. [CrossRef]

37. Zhang, L.L.; Zhu, D.; He, H.X.; Wang, Q.; Xing, L.L.; Xue, X.Y. Enhanced piezo/solar-photocatalytic activity of $\mathrm{Ag} / \mathrm{ZnO}$ nanotetrapods arising from the coupling of surface plasmon resonance and piezophototronic effect. J. Phys. Chem. Solids 2017, 102, 27-33. [CrossRef]

38. Chen, H.F.; Tan, C.L.; Zhang, K.; Zhao, W.B.; Tian, X.H.; Huang, Y.W. Enhanced photocatalytic performance of $\mathrm{ZnO}$ monolayer for water splitting via biaxial strain and external electric field. Appl. Surf. Sci. 2019, 481, 1064-1071. [CrossRef]

39. Freeman, C.L.; Claeyssens, F.; Allan, N.L.; Harding, J.H. Graphitic Nanofilms as Precursors to Wurtzite Films: Theory. Phys. Rev. Lett. 2006, 96, 066102. [CrossRef]

40. Claeyssens, F.; Freeman, C.L.; Allan, N.L.; Sun, Y.; Ashfold, M.N.R.; Harding, J.H. Growth of ZnO thin films-Experiment and theory. J. Mater. Chem. 2005, 15, 139-148. [CrossRef]

41. Deng, X.Y.; Yao, K.; Sun, K.J.; Li, W.X.; Lee, J.; Matranga, C. Growth of Single- and Bilayer ZnO on Au(111) and Interaction with Copper. J. Phys. Chem. C 2013, 117, 11211. [CrossRef] 
42. Tan, C.L.; Xu, D.S.; Zhang, K.; Tian, X.H.; Cai, W. Electronic and Magnetic Properties of Rare-Earth Metals Doped ZnO Monolayer. J. Nanomater. 2015, 2015, 329570. [CrossRef]

43. Wang, Q.B.; Zhou, C.; Wu, J.; Lu, T.; He, K.H. GGA+U study of the electronic and optical properties of hexagonal BN phase ZnO under pressure. Comput. Mater. Sci. 2015, 102, 196-201. [CrossRef]

44. Perdew, J.P.; Chevary, J.A.; Vosko, S.H.; Jackson, K.A.; Pederson, M.R.; Singh, D.J.; Fiolhais, C. Atoms, molecules, solids, and surfaces: Applications of the generalized gradient approximation for exchange and correlation. Phys. Rev. B 1992, 46, 6671-6687. [CrossRef] [PubMed]

45. Perdew, J.P.; Burke, K.; Ernzerhof, M. Generalized Gradient Approximation Made Simple. Phys. Rev. Lett. 1996, 77, 3865-3868. [CrossRef]

46. Hammer, B.; Hansen, L.B.; Norskov, J.K. Improved adsorption energetics within density-functional theory using revised Perdew-Burke-Ernzerhof functionals. Phys. Rev. B 1999, 59, 7413-7421. [CrossRef]

47. Wen, J.Q.; Zhang, J.M.; Chen, G.X.; Wu, H.; Yang, X. The structural, electronic and optical properties of Nd doped $\mathrm{ZnO}$ using first-principles calculations. Physica E 2018, 98, 168-173. [CrossRef]

48. Vanderbilt, D. Soft self-consistent pseudopotentials in a generalized eigenvalue formalism. Phys. Rev. B 1990, 41, 4892-7895. [CrossRef]

49. Monkhorst, H.J. Special points for Brillouin-zone integrations. Phys. Rev. B 1976, 16, 1748-1749. [CrossRef]

50. Majid, A.; Akram, W.; Dar, A. DFT study of electronic and structural properties of Sm:GaN. Comput. Mater. Sci. 2014, 88, 71-75. [CrossRef]

51. Hou, Q.Y.; Ji, X.F.; Xu, Z.C.; Zhao, C.W.; Qu, L.F. Effects of Li doping and point defect on the magnetism of ZnO. Ceram. Int. 2018, 44, 1376-1383. [CrossRef]

52. Tan, C.L.; Sun, D.; Tian, X.H.; Huang, Y.W. First-Principles Investigation of Phase Stability, Electronic Structure and Optical Properties of MgZnO Monolayer. Materials 2016, 9, 877. [CrossRef] [PubMed]

53. Ren, J.; Zhang, H.; Cheng, X.L. Electronic and Magnetic Properties of all 3d Transition-metal Doped ZnO Monolayers. Int. J. Quantum Chem. 2013, 113, 2243-2250. [CrossRef]

54. Chen, L.L.; Wang, A.P.; Xiong, Z.H.; Shi, S.Q.; Gao, Y.F. Effect of hole doping and strain modulations on electronic structure and magnetic properties in ZnO monolayer. Appl. Surf. Sci. 2019, 467, 22-29. [CrossRef]

55. Peng, Q.; Liang, C.; Ji, W.; De, S. A first principles investigation of the mechanical properties of g-ZnO: The graphene-like hexagonal zinc oxide monolayer. Comput. Mater. Sci. 2013, 68, 320-324. [CrossRef]

56. Mendoza-Estrada, V.; Gonzalez-Garcia, A.; Barragan-Yani, D.; Lopez-Perez, W.; Rivera-Julio, J.; Gonzalez-Hernandez, R. Ferromagnetic orderings in $\mathrm{Co}_{x} \mathrm{Cu}_{y} \mathrm{Zn}_{1-(x+y)} \mathrm{O}$ by GGA and GGA+U formalisms within density functional theory. Comput. Mater. Sci. 2017, 126, 344-350. [CrossRef]

57. Hussain, T.; Kaewmaraya, T.; Khan, M.; Chakraborty, S.; Islam, M.S.; Amornkitbamrung, V.; Ahuja, R. Improved sensing characteristics of methane over $\mathrm{ZnO}$ nano sheets upon implanting defects and foreign atoms substitution. Nanotechnology 2017, 28, 415502. [CrossRef]

58. Kohan, A.F.; Ceder, G.; Morgan, D. First-principles study of native point defects in ZnO. Phys. Rev. B 2000, 61, 15019-15027. [CrossRef]

59. Sun, Z.Q.; Liao, T.; Dou, Y.H.; Hwang, S.M.; Park, M.S.; Jiang, L.; Kim, J.H.; Dou, S.X. Generalized self-assembly of scalable two-dimensional transition metal oxide nanosheets. Nat. Commun. 2014, 5, 3813. [CrossRef]

60. Cheng, J.S.; Wang, P.; Hua, C.; Yang, Y.T.; Zhang, Z.Y. The Impact of Iron Adsorption on the Electronic and Photocatalytic Properties of the Zinc Oxide (0001) Surface: A First-Principles Study. Materials 2018, 11, 417. [CrossRef]

61. Zheng, H.Y.; Li, J.; Zhang, X.C.; Li, Z.; Xie, K.C. Structural and electronic properties of Cu-doped $\mathrm{Zn}_{5}(\mathrm{OH})_{6}\left(\mathrm{CO}_{3}\right)_{2}$ from first principles. J. Mater. Sci. 2015, 50, 6794-6807. [CrossRef]

62. Luan, Z.H.; Sun, D.; Tan, C.L.; Tian, X.H.; Huang, Y.W. First-principles calculations of electronic structure and optical properties of Be-doped ZnO monolayer. Integr. Ferroelectr. 2017, 179, 84-94. [CrossRef]

63. Saha, S.; Sinha, T.P.; Mookerjee, A. Electronic structure, chemical bonding, and optical properties of paraelectric $\mathrm{BaTiO}_{3}$. Phys. Rev. B 2000, 62, 8828-8834. [CrossRef]

64. Pawar, R.C.; Choi, D.H.; Lee, J.S.; Lee, C.S. Formation of polar surfaces in microstructured ZnO by doping with $\mathrm{Cu}$ and applications in photocatalysis using visible light. Mater. Chem. Phys. 2015, 151, 167-180. [CrossRef] 
65. Grzechulska-Damszel, J.; Morawski, A.W. Water Purification Using a Novel Reactor with Photoactive Refill. Catal. Lett. 2009, 127, 222-225. [CrossRef]

66. Jamil, T.S.; Ghaly, M.Y.; Fathy, N.A.; Abd el-halim, T.A.; Österlund, L. Enhancement of $\mathrm{TiO}_{2}$ behavior on photocatalytic oxidation of $\mathrm{MO}$ dye using $\mathrm{TiO}_{2} / \mathrm{AC}$ under visible irradiation and sunlight radiation. Sep . Purif. Technol. 2012, 98, 270-279. [CrossRef] 